OPEN ACCESS

Edited by:

Ramón Sotomayor-Zárate, University of Valparaíso, Chile

Reviewed by: Ventura Simonovich, Italian Hospital of Buenos Aires, Argentina

Romina Andrea Rojas-Ponce, University of Concepcion, Chile Raúl Vinet,

University of Valparaíso, Chile

${ }^{*}$ Correspondence:

Rodrigo L. Castillo rcastillo@med.uchile.cl; rodrigouch@gmail.com

Specialty section: This article was submitted to Translational Pharmacology, a section of the journa

Frontiers in Pharmacology

Received: 17 August 2019 Accepted: 16 December 2019 Published: 28 February 2020

Citation:

Castillo RL, Ibacache M, Cortínez I, Carrasco-Pozo C, Farías JG, Carrasco RA, Vargas-Errázuriz $P$,

Ramos $D$, Benavente $R$, Torres $D H$ and Méndez A (2020) Dexmedetomidine Improves

Cardiovascular and Ventilatory Outcomes in Critically III Patients: Basic and Clinical Approaches.

Front. Pharmacol. 10:1641. doi: 10.3389/fphar.2019.01641

\section{Dexmedetomidine Improves Cardiovascular and Ventilatory Outcomes in Critically III Patients: Basic and Clinical Approaches}

Rodrigo L. Castillo ${ }^{1,2 *}$, Mauricio Ibacache ${ }^{3}$, Ignacio Cortínez ${ }^{3}$, Catalina Carrasco-Pozo ${ }^{4}$, Jorge G. Farías ${ }^{5}$, Rodrigo A. Carrasco ${ }^{6}$, Patricio Vargas-Errázuriz ${ }^{2,7,8}$, Daniel Ramos ${ }^{1}$, Rafael Benavente ${ }^{1}$, Daniela Henríquez Torres ${ }^{1}$ and Anibal Méndez ${ }^{1}$

\begin{abstract}
1 Departamento de Medicina Interna Oriente, Facultad de Medicina, Universidad de Chile, Santiago, Chile, ${ }^{2}$ Unidad de Paciente Crítico, Hospital del Salvador, Santiago, Chile, ${ }^{3}$ Programa de Farmacología y Toxicología \& División de Anestesiología, Facultad de Medicina, Pontificia Universidad Católica de Chile, Santiago, Chile, ${ }^{4}$ Discovery Biology, Griffith Institute for Drug Discovery, Griffith University, Nathan, QLD, Australia, ${ }^{5}$ Departmento de Ingeniería Química, Facultad de Ingeniería y Ciencias, Universidad de La Frontera, Francisco Salazar, Chile, ${ }^{6}$ Departamento de Cardiología, Clínica AlemanaUniversidad del Desarrollo, Santiago, Chile, 7 Unidad de Paciente Crítico Adulto, Clínica Universidad de Los Andes, Santiago, Chile, ${ }^{8}$ Unidad de Paciente Crítico, Clínica Alemana-Universidad del Desarrollo, Santiago, Chile
\end{abstract}

Dexmedetomidine (DEX) is a highly selective $\alpha 2$-adrenergic agonist with sedative and analgesic properties, with minimal respiratory effects. It is used as a sedative in the intensive care unit and the operating room. The opioid-sparing effect and the absence of respiratory effects make dexmedetomidine an attractive adjuvant drug for anesthesia in obese patients who are at an increased risk for postoperative respiratory complications. The pharmacodynamic effects on the cardiovascular system are known; however the mechanisms that induce cardioprotection are still under study. Regarding the pharmacokinetics properties, this drug is extensively metabolized in the liver by the uridine diphosphate glucuronosyltransferases. It has a relatively high hepatic extraction ratio, and therefore, its metabolism is dependent on liver blood flow. This review shows, from a basic clinical approach, the evidence supporting the use of dexmedetomidine in different settings, from its use in animal models of ischemia-reperfusion, and cardioprotective signaling pathways. In addition, pharmacokinetics and pharmacodynamics studies in obese subjects and the management of patients subjected to mechanical ventilation are described. Moreover, the clinical efficacy of delirium incidence in patients with indication of non-invasive ventilation is shown. Finally, the available evidence from DEX is described by a group of Chilean pharmacologists and clinicians who have worked for more than 10 years on DEX.

Keywords: dexmedetomidine, cardiac, preconditioning, pharmacokinetics, non-invasive mechanical ventilation, sedative and analgesic properties 


\section{INTRODUCTION}

Dexmedetomidine (DEX), a pharmacological alpha 2-adrenergic agonist, which induces sympatholytic mechanism on the brain with anxiolytic and sedative effects (Cormack et al., 2005). DEX triggers the sedative pathways, causing a type of mild sedation and minimizing the risk of respiratory depression. This drug is mainly used in two settings: (1) in intensive care for moderate sedation, although it is not recommended for long-term sedation; and (2) in anesthesia as a stand-alone sedative or as co-adjuvant for general anesthesia. In both settings, DEX has shown interesting cardiovascular, respiratory, antiinflammatory, and organ protective properties. In clinic, it is used in perioperative sedation and intensive care, due to its analgesic and anxiolytics effects. The drug is commonly administered intravenously, either as a single bolus of approximately $1 \mu \mathrm{g} / \mathrm{kg}$ or as a bolus plus a continuous infusion ranging between 0.2 and $1 \mu \mathrm{g} / \mathrm{kg} / \mathrm{h}$. The stimulus of the different subtypes of $\alpha 2$-adrenergic receptors $(\alpha 2 \mathrm{~A}, \alpha 2 \mathrm{~B}, \alpha 2 \mathrm{C})$ and its location in the nervous system (pre or postsynaptic), will determine the different effects observed during use. Currently, many biological functions of DEX have been demonstrated in different animal models, through several signaling pathways.

Currently, the biological functions of DEX have been demonstrated in different animal models through several signaling pathways. Some studies demonstrate the beneficial effects of DEX against ischemia-reperfusi0on (I/R) injury (Riquelme et al., 2016; Deng et al., 2019), activating the eNOS/ NO cardioprotective signaling pathways. In vivo mechanistic studies are needed to determine the effects of DEX in clinical events that are associated with $I / R$. This review shows that DEX may be a pharmacological agent that modulates the organ $\mathrm{I} / \mathrm{R}$ injury responses in humans.

\section{PHARMACOKINETIC PROPERTIES}

DEX is an imidazole derivative with a $236.7 \mathrm{~g} / \mathrm{mol}$ molecular mass and a 2.89 octanol/water partition coefficient (Reel, 2019). Loading doses and infusion rates are determined on a milligram per kilogram total body weight (TBW). In general, linear pharmacokinetics adequately describes the body disposition of the drug, even after prolonged high dose administration in critically ill patients (Iirola et al., 2011a; Välitalo et al., 2013). However, patients with severe hepatic failure or obstructive jaundice have shown a reduction of metabolic clearance (CL) and significant changes in the volume of distribution (VD) (Cunningham et al., 1999; Song et al., 2018). DEX CL remains stable with dose increments within the therapeutic range and decreases with the administration of supratherapeutic doses (Dutta et al., 2000; Iirola et al., 2012).

Even though DEX was developed for intravenous use, it has been administered by different routes with variable bioavailability. Intramuscular administration has shown bioavailability of $103.6 \%$ with a time to peak of $1.7 \pm 1.8 \mathrm{~h}$ (Anttila et al., 2003). Nasal or buccal (submucosal) administration has been successfully used in patients without available venous access, avoiding high plasma peak levels. The bioavailability and time to peak of the nasal approach is 65\% (35-93\%) and 38 (15-60) min, respectively (Iirola et al., 2011b; Yoo et al., 2015). The bioavailability and time to peak of the buccal route is $81.8 \%(72.6-92.1 \%)$ and $1.5 \pm$ $0.2 \mathrm{~h}$, respectively. Due to an extensive first-pass effect, the bioavailability of the drug reaches only $15.6 \%$ after oral administration (Anttila et al., 2003). DEX has a high protein binding (94\%) with an extensive VD and easily crosses the bloodbrain barrier (Bhana et al., 2000). In non-compartmental kinetics, the administration of a single bolus has a $6.5 \pm 3.4 \mathrm{~min}$ distribution half-life (Anttila et al., 2003). The drug has a described steady state VD of 80-194 l, which is related to patient weight (Dyck et al., 1993; Khan et al., 1999; Välitalo et al., 2013). ICU patients tend to have greater variability of this parameter (109-223 1), and hypoalbuminemia has been shown to increase the VD in these patients (Iirola et al., 2012; Hodiamont et al., 2017).

The drug is extensively metabolized in the liver with a determined extraction ratio of 0.7 , and less than $1 \%$ of the drug eliminated without changes (Anttila et al., 2003). DEX undergoes $\mathrm{N}$-glucuronidation $(34 \%)$ by uridine diphosphate glucuronosyltransferases (UGT2B10, UGT1A4) and is also hydroxylated in a smaller proportion by the $\mathrm{P} 450$ enzyme system, specifically CYP2A6 (Adams and Murphy, 2000; Jorden and Tung, 2002; Kohli et al., 2012). The generated metabolites are approximately 100 times less potent than the original administered drug and are considered inactive. These metabolites are finally eliminated via the kidneys (95\%). The CL is 36-42 $\mathrm{l} / \mathrm{h}$ in average adult patients (Dyck et al., 1993; Khan et al., 1999). In ICU patients, CL has been defined at 31.8-57 1/h (Venn et al., 2002; Zhang et al., 2015). In healthy volunteers, the elimination half-life is $2.1-3.1 \mathrm{~h}$, and in ICU patients, the half-life slightly increases to 2.2-3.7 h (Karol and Maze, 2000; Venn et al., 2002; Zhang et al., 2015). In this context, the presence of hypoalbuminemia decreases or increases half-life times (Iirola et al., 2011a; Zhang et al., 2015). However, as a drug with a high hepatic extraction ratio, DEX CL would depend more on the blood flow to the liver (cardiac output) than on protein binding (Benet, 2002). It has been reported that a 19\% cardiac output reduction decreases DEX CL by 12\% (Dutta et al., 2000).

Numerous factors influencing the DEX dosage have been reported in the literature. Conditions such as hypoalbuminemia, liver dysfunction, reduced cardiac output, and hemodynamic alterations significantly affect both the VD and CL (Karol and Maze, 2000; Dutta et al., 2000; Zhang et al., 2015). Several pharmacokinetic models developed in different populations show that observed inter-individual variability of DEX body disposition is explained by the influence of the aforementioned covariates on pharmacokinetic parameters and patient dose requirements. Other covariates, such as ethnicity and polymorphisms of metabolic enzymes, are less relevant contributors to the described variability (Karol, 1996; Karol and Maze, 2000; Kurnik et al., 2008; Kohli et al., 2012).

In adults, the majority of these experimental models were derived from four trials of critically ill patients or healthy volunteers in which different DEX continuous infusions with 
varying durations were used. In most studies, a 2-compartment model adequately describes the disposition and elimination of DEX (Khan et al., 1999; Venn et al., 2002; Zhang et al., 2015; Cortinez et al., 2015). Fewer trials have described models of 1 and 3 compartments (Dyck et al., 1993; Dutta et al., 2000; Lin et al., 2011; Hannivoort et al., 2015). In these models, the VD has been correlated with patient age, TBW, free-fat mass (FFM), albuminemia, and the intercurrence of surgery. The CL varies according to patient height, TBW, FFM, albuminemia, and alanine aminotransferase metabolic activity. The review article by Weerink et al. evaluated the impact of different covariates on the DEX plasma concentration-time profile by means of comprehensive simulations (Weerink et al., 2017). For this purpose, a DEX $35 \mu \mathrm{g}$ loading dose infused over $10 \mathrm{~min}$, followed by a $35 \mu \mathrm{g} / \mathrm{h}$ maintenance dose was simulated supporting the different published pharmacokinetic simulations. In a $2 \mathrm{~h}$ DEX simulated infusion the authors found: 1) DEX reached concentrations after a bolus dose was directly dependent on patient albuminemia and inversely related to patient height, with a less significant influence of age on the observed maximum concentration; 2) the accomplished concentration during DEX infusion (steady state) was influenced by patient age, albuminemia, height, and body weight. These findings are in agreement with previously published data where age-associated metabolic CL reduction increases DEX plasma concentration in patients (Iirola et al., 2012). Albuminemia and height may also influence DEX concentrations, but their impact is less clear compared to other more relevant covariates (Lin et al., 2011; Lee et al., 2012; Zhang et al., 2015). For instance, available evidence suggests that DEX CL is significantly influenced by hepatic blood flow and cardiac output, but since DEX likely has a high hepatic extraction ratio, this influence is difficult to establish in all populations. However, the non-linear behavior of DEX CL has been described in noncompartmental and compartmental analyses where DEX concentration increments reduce the drug CL by reducing cardiac output (Dutta et al., 2000; Iirola et al., 2012). At present, changes in TBW or FFM have a significant impact on concentrations after a bolus and during the infusion of DEX and should be considered when dosing adult patients (Cortinez et al., 2015; Hannivoort et al., 2015; Kuang et al., 2016).

As previously mentioned, TBW emerges as a significant covariate that influences the concentrations of DEX. Infusion schemes using mass units of drug per kilogram of TBW do not seem appropriate for the obese individual, as they result in increased plasma levels than those observed in lean subjects. In a pharmacokinetic modeling analysis by Cortinez et al., lean tissues showed as fat-free mass (FFM) accounted for sizedependent changes in VD of DEX (Cortinez et al., 2015). In addition, they also showed that for any lean body mass, total CL decreased associated with major fat mass. In a second trial by the same study group, authors confirmed that lean body mass was an appropriate dosing scalar for size in obese patients and showed that decreased hepatic blood had a significant effect on the CL of DEX (Rolle et al., 2018). The observed CL reduction in this population is most probably explained by a relative overdose of obese patients caused by TBW-based dosing schemes. In this setting, scaling doses to FFM or allometric TBW seems more relevant (Cortinez et al., 2015; Hannivoort et al., 2015; Rolle et al., 2018).

Although the drug is not approved for clinical administration in the pediatric population, its off-label use is widely extended in these patients (Mahmoud and Mason, 2015). DEX pharmacokinetics in children has been studied in ICU patients and in patients undergoing cardiac and non-cardiac surgery (Potts et al., 2009; Su et al., 2010; Wiczling et al., 2016; Su F. et al., 2016; Liu et al., 2017). A 2-compartment model, using TBW scaled to 1 for the VD and 0.75 for the CL (Equation 1), adequately describes the disposition of the drug in pediatric populations.

$$
\mathrm{y}=\mathrm{a} \llbracket \mathrm{TBW} \rrbracket \wedge \mathrm{PWR}
$$

where $\mathrm{y}$ is the variable of interest (e.g., $\mathrm{Cl}$ or $\mathrm{V}$ ), a is the allometric coefficient, and PWR is the allometric exponent.

In children, $93 \%$ of DEX is protein bound with a rapid redistribution half-life of approximately $7 \mathrm{~min}$ and elimination half-life of 2 h (Petroz et al., 2006; Mason and Lerman, 2011). Weight appears as a significant covariate influencing DEX CL in children older than 2 years with nearby levels (within 30-40\%) to those reported in adults (Petroz et al., 2006). Several studies report the influence of the maturation of neonatal enzymatic activity on CL, but the available data are very dissimilar. At birth, a full-term neonate has a DEX CL of $43-54 \%$ adult values, and in a variable period ( 1 month-1 year) reaches adult values (Potts et al., 2009; Wiczling et al., 2016). Overall, allometric scaling can be used to predict DEX concentrations in children older than 1 year of age. In children younger than 1 year, inter-individual variability significantly influences the CL and is substantially greater than the impact of maturation on this parameter. Thus, despite considering maturation and patient age, it is difficult to achieve a certain predicted concentration in very small children.

\section{PHARMACODYNAMIC PROPERTIES}

In terms of the pharmacodynamic properties of DEX, it shows a high affinity and selectivity for the $\alpha 2$-adrenoceptors, this pharmacological characteristic determines a typical biphasic hemodynamic response. After infusion, DEX induces sympatholytic effect, such as a lower mean arterial blood pressure (MAP) and heart rate (HR) through activation of presynaptic $\alpha 2$-adrenoceptors in the central nervous system. In addition, DEX induces vasodilation through activation of $\alpha 2$ adrenoceptors in endothelial cells (Figueroa et al., 2001; Talke et al., 2003). At higher concentrations, vasoconstrictive effects of DEX are attributable to activation of $\alpha 2$-adrenoceptors in vascular smooth muscle, resulting clinically in an increase in MAP and diminution of HR (Snapir et al., 2006). The pharmacokinetic and pharmacodynamic effects of DEX have been extensively studied in animal models, however its role in critical patients' arterial pressure and heart rate has been scarcely addressed (Ebert et al., 2000; Snapir et al., 2006; Potts et al., 2010). 


\section{Adverse Effects}

Adverse effects of dexmedetomidine are mainly restricted to hemodynamic alterations. These include hypertension, bradycardia, and hypotension owing to pre- and postsynaptic $\alpha 2$-receptor activation, which causes vasoconstriction, vasodilatation, and reflex bradycardia (Ebert et al., 2000). Long-term use of dexmedetomidine leads to super sensitization and upregulation of receptors. With abrupt discontinuation, a withdrawal syndrome of nervousness, agitation, headaches, and hypertensive crisis can occur.

Common adverse effects for organ systems (1 to 10\%) are: respiratory, Atelectasis, hypoxia, pulmonary edema, pleural effusion, respiratory failure, acute respiratory distress syndrome, bradypnea, pneumonia, pharyngolaryngeal pain, gastrointestinal, dry mouth, vomiting, constipation, abdominal distension, abdominal pain, diarrhea, hematologic, anemia, metabolic, hyperglycemia, hypoglycemia, hypocalcemia, acidosis, hypokalemia, hypomagnesemia, hypernatremia, hypophosphatemia, acute renal failure, and oliguria (Cheung et al., 2014).

Dexmedetomidine is not recommended in patients with advanced heart block and ventricular dysfunction. FDA has classified it as a category $\mathrm{C}$ pregnancy risk, therefore the drug should be used with extreme caution in women who are pregnant (Morgan et al., 2006).

Two major limitations regarding dexmedetomidine use, are its long-lasting effects and its hemodynamic side effects. A safe and quick reversal of these effects would benefit clinical practice, presumably leading to more widespread use of dexmedetomidine. The selective $\alpha 2$-antagonist atipamezole can effectively reverse dexmedetomidine's hemodynamic and sedative effects (Karhuvaara et al., 1991). The reduction in heart rate and blood pressure caused by dexmedetomidine is quickly reversed after IV administration of $15-150 \mu \mathrm{g} / \mathrm{kg}$ atipamezole. Higher doses of atipamezole $(150 \mu \mathrm{g} / \mathrm{kg})$ also reverse sedation. Transient orthosympathic activation, with a 10 -fold increase in plasma norepinephrine levels, is seen with higher doses or fast infusion rates (Scheinin et al., 1998).

\section{Effects on Cardiovascular and Ventilatory Physiology}

The US Food and Drug Administration (FDA) originally approved DEX for use in "initially intubated, mechanically ventilated patients," that is, in ventilated patients requiring sedation throughout and after extubation. Then Hanna and Milap, (2008) approved its use for the sedation of non-invasive intubated critical patients (Panzer et al., 2009; Keating et al., 2012). Since DEX's appearance on the market as a sedative drug, cardiovascular and ventilatory effects have been extensively characterized (Deutsch and Tobias, 2007).

The effects of DEX on the cardiovascular system are a consequence of the pharmacological modulation of the $\alpha-2$ adrenergic receptor. The stimulation of the different subtypes of $\alpha 2$ adrenergic receptors $(\alpha 2 \mathrm{~A}, \alpha 2 \mathrm{~B} \alpha 2 \mathrm{C})$ and their location in the nervous system (pre or postsynaptic), will determine the different cardiovascular effects observed during its use. An intravenous bolus of DEX in healthy individuals determines a biphasic blood pressure response. DEX infusion induces an initial transient increase vasoconstriction in vascular smooth musculature (by activation of postsynaptic $\alpha 2 \mathrm{~B}$ receptors), followed by a decrease in blood pressure and heart rate (by the activation of $\alpha 2 \mathrm{~A}$ receptors in the central nervous system). This apparent dual action of the drug becomes evident when its effect is considered in sympathetically denervated territories, such as when an anesthetic blockade of peripheral nerve exists (Talke et al., 2003) or when high doses of the drug are used. In these situations, the peripheral vasoconstrictor effect of the drug predominates. The opposite effect, vasodilation associated with central sympatholysis is observed when low doses are used in subjects with a non-intervened sympathetic system. The omission of the DEX loading bolus prevents initial hypertension and reflex bradycardia (Ickeringill et al., 2004). In addition, stimulation of postsynaptic $\alpha 2$-adrenergic receptors in endothelial cells would also induce vasodilation. In this context, the correct infusion rate of the drug, appropriate volume administration and clinical indication, make DEX a substance with a wide security therapeutic range (Kamibayashi and Maze, 2000). The central inhibition of the sympathetic system could minimize patient stress and instability in blood pressure during and after cardiac surgery (Gong et al., 2017). Evidence suggests that induced autonomic nervous system modulation during perioperative administration of DEX is associated with a trend towards improved cardiac outcomes following noncardiac surgery (Biccard et al., 2008; Wijeysundera et al., 2009). In addition, this central inhibition of sympathetic discharge could prevent the sympathetic reservoir from being depleted, and therefore the Dex group has higher blood pressure compared to the control group. Mukhtar et al. used a dosage of $0.5 \mu \mathrm{g} / \mathrm{kg} / \mathrm{h}$ by infusion, which was effective in diminishing the hemodynamic response to surgery without deleterious vasodepressor effects (Mukhtar, 2006).

Despite the deep sedative effects, DEX is associated with minor respiratory depression, even when it is dosed in plasma levels up to 15 times with those usually obtained during administration, offering a higher level of safety, compared with other sedative agents (Venn et al., 2000; Filbey et al., 2014). Hypercapnic stimulation is preserved and limits apnea or attenuates the stimulatory effect of $\mathrm{CO} 2$ levels. In volunteers, DEX infusions preserved the hypercapnic ventilatory response, the respiratory rate was significantly increased, and the overall apnea/hypopnea index was significantly decreased. The distribution of inspiratory time/ventilatory cycle time showed an increased peak. More importantly, DEX exhibited a hypercapnic arousal phenomenon similar to that which has been described during natural sleep (Hsu et al., 2004). Compared with opioid infusions, DEX can be infused by a tracheal tube in a safe manner (Panzer et al., 2009).

\section{DEX Molecular Pathways}

DEX modulates some intracellular pathways such as $G$ proteincoupled receptors, protein kinase $\mathrm{C}$ (PKC) activity, and inositol triphosphate (IP3) levels in renal cells. Protein kinase $\mathrm{C}$ is relevant as an ischemic preconditioning trigger providing organ protection, the opening mitochondrial ATP-sensitive $\mathrm{K}+$ channels, and the 
induction of protective gene transcription (Curtis et al., 2011). DEX determines the in vitro activation of the adenylyl cyclasecyclic adenosine monophosphate (cAMP), suggesting that DEX may have a protective effect through the modulation of PKC activation-induced HSP27 phosphorylation (Tanabe et al., 2008; Tanabe et al., 2010). The $\alpha 2$-AR-focal adhesion kinase-Srcphosphatidylinositol 3-kinase (PI3K)-protein kinase B (Akt) (Girault et al., 1999; Parcellier et al., 2008), and the mitochondrial ATP-sensitive $\mathrm{K}+$ channel pathways are involved in the preconditioning and postconditioning mechanisms induced by DEX against hippocampal oxidative damage (Dahmani et al., 2008; Dahmani et al., 2010). Treatment with DEX reduces central nervous injury in rats subjected to focal $I / R$, which is mediated by the activation of the PI3K/Akt and ERK1/2 pathways (Zhu et al., 2013). Moreover, DEX attenuates hippocampal CA1 long-term potentiation. $\alpha 2$-ARs and imidazoline I2 receptors are modulated by DEX (Takamatsu et al., 2008). Regarding the neuroprotective effects, epidermal growth factor receptor activation in astrocytes in vivo represents an important process secondary to $\alpha 2$-AR activation (Du et al., 2009). Moreover, the $\alpha 2$-ARs also activate the mitogen-activated protein kinase pathway and thus determine the proliferation of tubular cells derived from the human intestinal epithelium in rats. (Schaak et al., 2000; Cussac et al., 2002; Karkoulias et al., 2006).

Previous animal experiments have shown benefits and cardioprotective effects of DEX administration in the ischemic heart (Roekaerts et al., 1996; Willigers et al., 2003; Okada et al., 2007). Furthermore, it has been shown that DEX administration causes activation of signaling pathways associated with cardiac survival. The DEX pretreatment of rat hearts induces Erk 1/2, Akt and eNOS activation, improves myocardial function and reduces myocardial infarction size after regional ischemiareperfusion (I/R) of the heart in the in vivo and ex vivo models (Ibacache et al., 2012). In this study, the three isotypes of $\alpha 2$ adrenergic receptors were detected in the whole cardiac tissue and the $\alpha 2 \mathrm{~A}$ and $\alpha 2 \mathrm{C}$ adrenergic receptors were detected only in isolated cardiomyocytes. The authors concluded that independently from autonomic nervous system modulation, DEX cardioprotective effects are mediated by activation of prosurvival PI3K/Akt signaling pathway after cardiac $\alpha 2$-adrenergic receptor stimulation. More recent studies have demonstrated the role of endothelial $\alpha 2$-adrenergic receptors with beneficial effects on DEX against I/R injury (Riquelme et al., 2016; Deng et al., 2019), activating the eNOS/NO cardioprotective signaling pathways (Kim et al., 2009).

\section{Molecular Mechanisms of Dexmedetomidine Effects on Heart and Lung}

The mitochondria are critical coordinators of cellular life through their function on bioenergetics, producing energy, and their role in apoptosis, regulating cell death (Wang and Youle, 2009). The mitochondria supply $90 \%$ of the cardiomyocyte ATP, which is necessary to support contraction, metabolism, and ion homeostasis, and thus have a critical role in cardiac function (Harris and Das, 1991; Pohjoismäki and Goffart, 2017).
Mitochondrial dysfunction has been involved in the pathophysiology of cardiovascular disease, including ischemia/ reperfusion (I/R) injury, arrhythmogenesis, and left ventricular dysfunction (Lesnefsky et al., 2001; Chen et al., 2018a; Chen et al., 2018b). It has been shown that DEX preconditioning rat cardiomyocytes through mitochondrial protection diminishes reactive oxygen species (ROS)-induced apoptosis (Liu et al., 2018; Weng et al., 2018). Dexmedetomidine prevented the increase in the oxygen consumption rate and ROS levels induced by $\mathrm{H} 2 \mathrm{O} 2$. It improved the coupling efficiency of the mitochondria potentially by preserving mitochondrial membrane potential (MMP) in the presence of mitochondrial uncouplers (Liu et al., 2018; Weng et al., 2018). Moreover, dexmedetomidine decreased the $\mathrm{H} 2 \mathrm{O} 2$-induced activity of caspase 12, and the mRNA levels of Grp78 (glucose regulated protein $78 \mathrm{kDa}$ ) and IRE1 $\alpha$ (serine/threonine protein kinase/ endoribonuclease), three signaling pathways that determine ER stress mediated cell death (Liu et al., 2018). The cardioprotective effect of DEX has also been evidenced in isolated rat hearts, in which DEX preconditioning $(10 \mathrm{nmol} / \mathrm{l}$ before ischemia for 15 min) had protective effects against I/R injury. The agonist attenuates myocardial cell death and improves cardiac function through mechanisms that involve the inhibition of the mitochondrial permeability transition pore (mPTP) opening at reperfusion time (Jiang et al., 2013). The opening of the mPTP results in respiratory chain uncoupling, mitochondrial ATP synthesis reduction, mitochondrial swelling and cell death (Hunter and Haworth, 1979; Halestrap, 2009). Thus, the mPTP is a selective pharmacological target for cell death prevention in pathophysiological conditions. Cyclophilin D, a regulator of the $\mathrm{mPTP}$, protects against cell death in response to different injuries (Millay et al., 2008; Martin et al., 2009; Ramachandran et al., 2011). The protection of the mitochondrial function, by inhibiting the MPTP opening and thus preserving the MMP, is a plausible mechanism by which DEX exerts its cardioprotective effects.

As an anesthesia co-adjuvant, dexmedetomidine can improve hemodynamic stability and reduce the doses of anesthetics and analgesics during surgery, and it may contribute to the prevention of postoperative cognitive dysfunction (POCD) (Carr et al., 2018). In patients undergoing elective surgery under general anesthesia induced by remifentanil $(0.5-1 \mu \mathrm{g} / \mathrm{kg} /$ h) and propofol $(3-10 \mathrm{mg} / \mathrm{kg} / \mathrm{h})$, the addition of dexmedetomidine $(0.2 \mu \mathrm{g} / \mathrm{kg} / \mathrm{h})$ during induction and maintenance periods improved POCD, through the mechanism involving mitochondrial function protection. Dexmedetomidine attenuated the decrease in postoperative National Institutes of Health Stroke Scale (NIHSS) and Auditory Verbal Learning Test (AVLT) scores and the increase in the Beck Depression Inventory (BDI) score. In terms of mitochondrial function, dexmedetomidine alleviated the postoperative decrease in mitochondrial membrane potentials and the activities of the mitochondrial respiratory complexes IIV in leukocyte cells (Chen et al., 2018a; Chen et al., 2018b). Moreover, dexmedetomidine has been shown to have neuroprotective effects against apoptosis through mechanisms involving mitochondrial functions (Flatters and Bennett, 2006). 
Apoptosis is a major pathway in I/R-induced neuronal and cardiac insults (Borgens and Liu-Synder, 2012). Dexmedetomidine prevented apoptosis induced by $\mathrm{I} / \mathrm{R}$ by protecting against MMP reduction, Bax and cytochrome $\mathrm{c}$ release as well as caspase activation in neuro-2a and NB41A3 neuronal cells ( $\mathrm{Wu}$ et al., 2017). Dexmedetomidine also protected PC12 cells from lidocaine-induced apoptosis, diminished the mRNA levels of COL3A1, increasing Bcl2, and inhibiting caspase 3 activation (Wang et al., 2017). Interestingly, this effect was reversed by the miR-let-7b inhibitor, indicating that dexmedetomidine exerts neuroprotection via miR-let-7b, a recognized modulator of mitochondrial function (Barrey et al., 2011; Wang et al., 2017). Dexmedetomidine protected PC12 cells against glutamate-induced cytotoxicity through its mitochondrial protective effect, stabilizing $\mathrm{MMP}$ and $\mathrm{Ca} 2+$ homeostasis, and through its antioxidant properties, reducing malondialdehyde and augmenting superoxide dismutase activity (Zhang et al., 2016).

In addition, DEX has demonstrated neuroprotective effects against ischemia or tissular hypoxia. In an in vivo neuroprotection model, DEX prevented the brain damage induced by cerebral ischemia-reperfusion in rats by activating mitochondrial ATP-sensitive potassium channel (mitoKATP) (Yuan et al., 2017). Dexmedetomidine (50 $\mu \mathrm{g} / \mathrm{kg}$ injected intraperitoneally before ischemia and after onset of reperfusion) prevented the I/R-induced increase in the neurological deficit score, pro-oxidant enzyme activity (such as myeloperoxidase and malondialdehyde) in the brain and proinflammatory cytokine levels in plasma (like IL-6 and TNF- $\alpha$ ) (Yuan et al., 2017). The neuroprotective mechanism by DEX was not observed in the presence of 5-hydroxydecanoate, a mito-KATP channel blocker, which suggests that its pharmacological target involves mitochondrial components (Yuan et al., 2017).

Acute lung injury (ALI) is a common condition in critical patients, and lipopolysaccharide (LPS) is the most important pathogen that determines the development of ALI in sepsis (Gonzales et al., 2014). Dexmedetomidine has been reported to attenuate LPS-induced ALI in rats (Hanci et al., 2012; Fu et al., 2017). Specifically, DEX (50 $\mu \mathrm{g} / \mathrm{l} 30 \mathrm{~min}$ prior to LPS cell treatment) diminished LPS-induced mitochondrial dysfunction by preventing the reduction in cellular ATP levels and MMP in rat type I alveolar epithelial cells (AECs) (Fu et al., 2017). In addition, the same concentration of DEX markedly reduced the LPS-induced mitochondrial-dependent apoptotic pathway in AECs, as the $2 \alpha$-adrenoreceptor agonist decreased the cytosolic cytochrome $c$ and caspase 3 activity (Liu et al., 2018). In vivo dexmedetomidine (50 ug/kg, $30 \mathrm{~min}$ prior LPS administration) also decreased LPS-induced apoptosis, as demonstrated by attenuating DNA fragmentation, activation of caspase 3, Bax upregulation and Bcl-2 downregulation in lungs. Furthermore, DEX markedly diminished LPS-induced oxidative stress, as evidenced by the downregulation of cellular ROS in AECs and lipidperoxidation levels in serum (Fu et al., 2017). Moreover, dexmedetomidine treatment inhibited hyperoxia or the LPS/ ATP-induced decrease of MMP and mitochondrial ROS production in RAW264.7 cells; therefore, through this mechanism, dexmedetomidine restrained the NLRP3 inflammasome activation-mediated increased release of IL-1 $\beta$, IL-18, and TNF- $\alpha$ (Zhang et al., 2017). Dexmedetomidine may contribute to reducing ALI, by preventing the activation of macrophages through a mechanism that involves mitochondrial protections or by inducing neutrophil cell death, also by targeting the mitochondria (Kishikawa et al., 2008). Dexmedetomidine (100 ng/ml, $24 \mathrm{~h}$ incubation) has been shown to induce apoptosis in neutrophils through mechanisms involving caspase cascade activation and mitochondrial intrinsic pathway triggered by decreasing the MMP (Kishikawa et al., 2008). In the intrinsic pathway, loss of MMP induces the mitochondrial disruption, and mitochondrial pro-apoptotic proteins are released into the cytosol, triggering the activation of caspase-9 (Wang and Youle, 2009). Interestingly, DEXinduced apoptosis is unlikely to be $2 \alpha$-adrenoreceptormediated, as yohimbine, a $2 \alpha$-adrenoreceptor antagonist, did not attenuate its pro-apoptotic effects (Kishikawa et al., 2008). As the pro-apoptotic effect of dexmedetomidine is evidenced at a concentration 100-times greater than is considered clinically relevant $(1 \mathrm{ng} / \mathrm{ml})$, the clinical administration is safe for ICU patients.

The molecular signaling pathways trigger by DEX, and pathophysiological effects are shown in Figure 1.

\section{CLINICAL EFFICACY FOR THE USE OF DEX IN DIFFERENT CLINICAL SETTINGS}

Diverse effects of DEX include sedation, analgesia, anxiolysis, sympatholysis, cardiovascular stabilization and reduction of anesthetic requirements with preservation of respiratory function (Bhana et al., 2000; Kaur and Singh, 2011; Mahmoud and Mason, 2015). Although labeled for short-term sedation only ( $24 \mathrm{~h}$ or less), its use has been demonstrated to be safe for long-term sedation in critically ill patients (Ozaki et al., 2014), in whom pharmacokinetics is often unpredictable (Weerink et al., 2017). Other important benefits are its easy dosage titration (reducing oversedation risk), its several routes of administration, and minimal clinical impact of its metabolites (Devlin, 2008; Gerlach et al., 2009). These features have given DEX an advantage over other sedatives, such as opioids and benzodiazepines. Its clinical use has been focused on two major scenarios: periprocedural sedation in anesthesia and "light to mild" sedation in the ICU (Arcangeli et al., 2009).

\section{DEX as Peri-Procedural Sedation in Anesthesia}

The unique properties of DEX make it suitable for sedation and analgesia during the entire perioperative state in a wide range of procedures (Table 1). DEX can be used as premedication, as an anesthetic adjunct for anesthesia or as a postoperative sedative process. This versatility is further enhanced by the property of being compatible with practically all administration routes used in usual perioperative care (Table 2). This is particularly useful in pediatrics, non-collaborative patients, or those with insufficient 


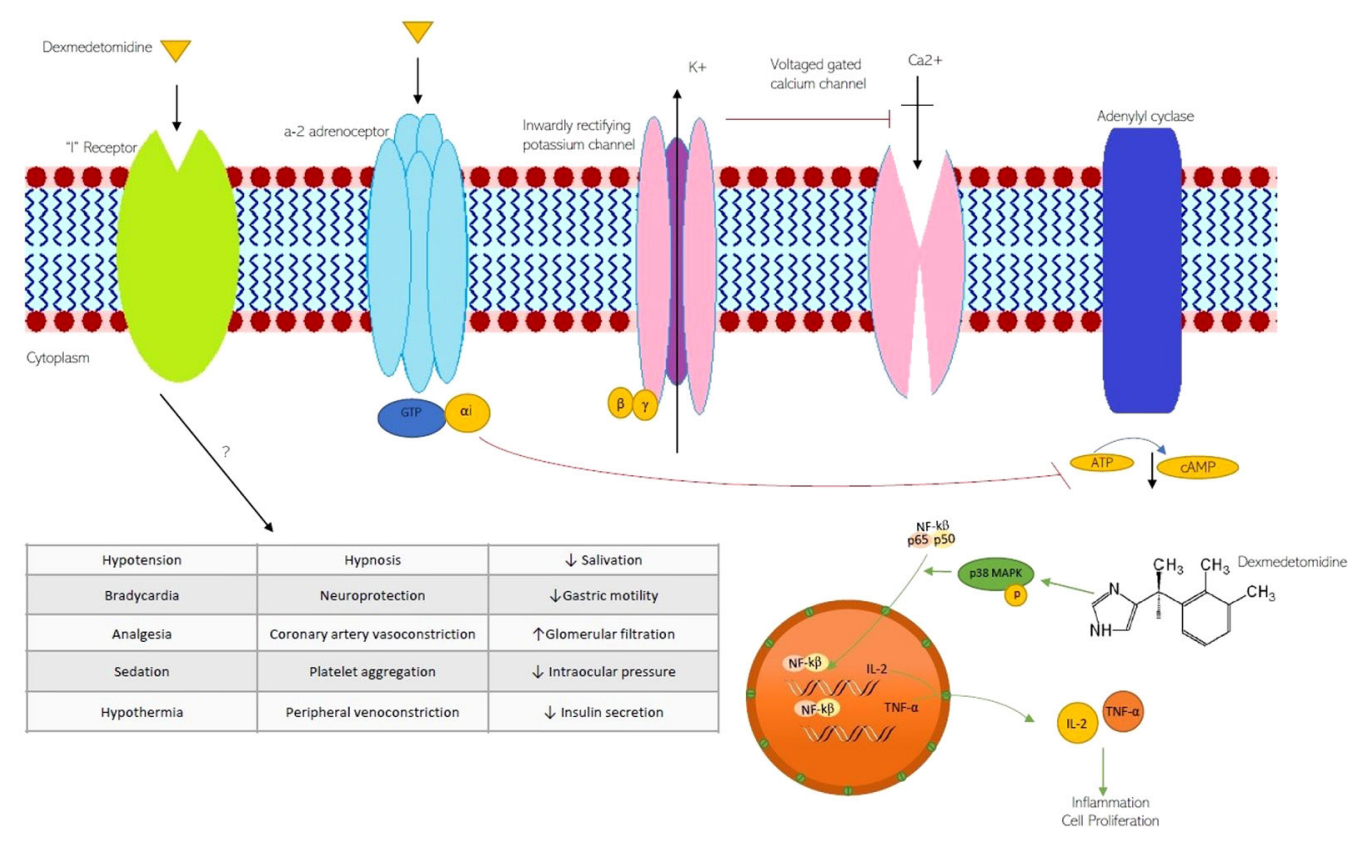

FIGURE 1 | The molecular signaling pathways trigger by DEX and pathophysiological effects on ion channels and G-protein-coupled receptors. $\mathrm{K}^{+}$, potassium channel; $\mathrm{Ca}^{2+}$ calcium channel; GTP guanosine triphosphate; $\alpha$ a alpha inhibitory unit; CAMP c- adenosine monophosphate; NF-kB nuclear factor kappaB; MAPK, Mitogen-Activated Protein Kinases.

TABLE 1 | Reported use of DEX in several settings of perioperative care.
Epidural anesthesia

Spinal anesthesia

Caudal anesthesia

Peripheral nerve block

Intraarticular use (Arthroscopic surgery)

Intensive care unit sedation

Transesophageal echocardiography

Colonoscopy

Awake carotid endarterectomy

Awake intubation

Vitreoretinal surgery

Tonsillectomy/Adenoidectomy

Shockwave lithotripsy

Attenuated response to tracheal intubation and

extubation

Post-operative analgesia

Cardiac surgery

Neurosurgery

Sedation in obese patients

Use in MRI

Endoscopic retrograde cholangio-

pancreatography

Ureteroscopy

\section{Schnaider et al., 2005}

Kanazi et al., 2006

El-Hennawy et al., 2009

Dai et al., 2018

Al-Metwalli et al., 2008

Riker et al., 2009

Cooper et al., 2011

Jalowiecki et al., 2005

Bekker et al., 2004

Bergese et al., 2007

Ghali et al., 2011

Olutoye et al., 2010/Li et al.,

\section{8}

Kaygusuz et al., 2008

Guler et al., 2005

Venn et al., 1999

Wijeysundera et al., 2003

Bekker et al., 2008/Bekker

et al., 2013

Hofer et al., 2005

Mason et al., 2008

Lu et al., 2018

Shariffuddin et al., 2018 venous access (Scott-Warren and Sebastian, 2016; Weerink et al., 2017; Sottas, 2017).

Several meta-analyses have evaluated the use of DEX in the perioperative period. Piao and Wu (2014) focused on cardiovascular stress response to surgical injury. They found patients receiving DEX had significantly lower blood pressure and heart rate. Conversely, they also found more hypotension and bradycardia. In an earlier publication, Sun et al. (2008) found that DEX reduced the amount of intravenous and inhaled anesthetics, but did not reduce muscle relaxant dosages. Other authors have shown a reduction in postoperative delirium (see below), pain (Schnabel et al., 2013a; Schnabel et al., 2013b; Huang et al., 2015) and shivering (Lewis et al., 2015; Liu et al., 2015; Hoffman and Hamner, 2016). The effect of DEX on postoperative shivering is still not well understood (Lopez, 2018). Although some positive results have been shown in clinical trials, the evidence is still regarded as poor. Moreover, DEX is not superior to other anti-shivering agents, such as fentanyl, meperidine, tramadol or clonidine.

\section{DEX in the ICU}

Sedatives are administered to critically ill patients to alleviate discomfort, prevent agitation-related harm, decrease metabolic demand (reducing $\mathrm{O}_{2}$ consumption and $\mathrm{CO}_{2}$ production), and improve tolerance and adaptation to mechanical ventilation (Taittonen et al., 1997; Chlan et al., 2017). In order to reduce the adverse events associated with sedative drugs, clinical guidelines have been issued (Barr et al., 2013; Devlin et al., 2018). One of the principal indication for the use of DEX is to alleviate the pain and induce sedation in critical patients by targeting light levels of sedation. However, its administration is not recommended in acute respiratory distress syndrome (ARDS), shock or intracranial 
TABLE 2 | Dosage of DEX used in several administration routes.

\begin{tabular}{|c|c|c|}
\hline Route & Dosage & \\
\hline Intravenous & $\begin{array}{l}\text { For ICU sedation } 0.2-1.4 \mathrm{mcg} / \mathrm{kg} / \mathrm{h} \text {, } \\
\text { may start } \\
1.0 \mathrm{mcg} / \mathrm{kg} \text { bolus } \\
\text { For Procedural sedation } 0.2-1 \mathrm{mcg} / \mathrm{kh} / \mathrm{h}\end{array}$ & Riker et al., 2009 \\
\hline Intranasal & $1-2 \mathrm{mcg} / \mathrm{kg}$ & Cimen et al., 2013 \\
\hline Buccal & $1-2 \mathrm{mcg} / \mathrm{kg}$ & Cimen et al., 2013 \\
\hline Intramuscular & $2.5 \mathrm{mcg} / \mathrm{kg}$ & Sun et al., 2014 \\
\hline Spinal & $0.1-0.2 \mathrm{mcg} / \mathrm{kg}$ & Kanazi et al., 2006 \\
\hline Epidural & $1-2 \mathrm{mcg} / \mathrm{kg}$ & $\begin{array}{l}\text { Schnaider et al., } \\
2005\end{array}$ \\
\hline $\begin{array}{l}\text { Peripheral nerve } \\
\text { block }\end{array}$ & $1 \mathrm{mcg} / \mathrm{kg}$ & $\begin{array}{l}\text { Obayah et al., } \\
2010\end{array}$ \\
\hline
\end{tabular}

hypertension. These recommendations match in many aspects, the pharmacological and clinical properties of DEX, explaining its increasing use in intensive care units (DeBiasi et al., 2015).

Among the main reported benefits associated with DEX use in the ICU are shorter ICU stays and mechanical ventilation duration (Chlan et al., 2017), less use of benzodiazepines, and lower incidence of delirium ( $\mathrm{Su}$ X. et al., 2016; Nunes et al., 2018). Conversely, bradycardia and hypotension occurrence have been described in ICU patients with a minimal impact on mortality (Barr et al., 2013; Constantin et al., 2016; Devlin et al., 2018).

\section{DEX in Invasive Mechanical Ventilation}

As noted earlier, one of the main indications of sedoanalgesia in the ICU is to improve tolerance and adaptation to mechanical ventilation, as the prevalence of anxiety and agitation in ventilated patients of up to $80 \%$ has been reported (Tate et al., 2012; Chlan et al., 2017). Conversely, in the case the use of oversedation in ICU patients the deleterious effects are evidenced. In this case, the clinical effects include: increase in the occurrence of delirium, immobility, respiratory muscle atrophy, long-term mechanical ventilation duration, prolonged of ICU stays, and increased costs and even a rise in mortality (Rodrigues Júnior and do Amaral, 2004; Wunsch, 2012; Kress and Hall, 2014; Reade and Finfer, 2014). Thus, the optimal management of sedation in this scenario has been the subject of extensive debate. For a better understanding of this issue, it is essential to distinguish between two different scenarios where mechanical ventilation is frequently used. The first involves an unstable patient, where deep sedation is required, often associated with a neuromuscular blockade, and where protective ventilation is sought. This patient needs complete suppression of spontaneous respiratory effort, with the physiological objective of reducing the associated pulmonary injury (Yang and Kang, 2017), decreasing metabolic demand (Kumba and Van der Linden, 2008) or reducing intracerebral pressure (Oddo et al., 2016). Examples of this situation include ARDS, severe shock, or unstable intracranial hypertension. In these settings, the use of DEX does not seem to have a role.
In the second scenario, the patient has a less severe condition than the one previously described. Clinical stability has been reached, the cause that led to ICU admission is in clear resolution, resuscitation has been completed, or the effort for strict "pulmonary protection" has ceased. In other words, the patient has entered the "dereanimation" phase (Silversides et al., 2017), where the target is the reduction of the morbidity attributed to the interventions carried out in the ICU. In this scenario, it is highly likely that a more superficial sedation, which favors controlled spontaneous ventilatory effort, mobility, and awakening, will produce better clinical outcomes. DEX has a role in this setting and has indeed shown optimal outcomes in clinical trials (Fraser et al., 2013; Hayashida et al., 2016).

In summary, in patients undergoing mechanical ventilation in the ICU who do not require deep sedation, the use of DEX is associated with fewer days in the ICU, shorter time to extubation and a decrease in the incidence of delirium, although no differences in mortality have been shown (Reade and Finfer, 2014; Su X. et al., 2016; Nunes et al., 2018).

\section{DEX in Non-Invasive Ventilation}

Non-invasive ventilation (NIV) has shown to be beneficial in the treatment of acute respiratory failure associated with acute cardiogenic pulmonary edema, chronic obstructive pulmonary disease and postoperative care, amongst others (Jaber et al., 2010; Osadnik et al., 2017; Bello et al., 2018). These benefits are mainly explained by decreasing the need for intubation and connection to mechanical ventilation (Osadnik et al., 2017; Bello et al., 2018). One of the leading causes of NIV failure is agitation, non-tolerance, and non-cooperative patient, reaching rates of up to $22 \%$ (Carlucci et al., 2001). In these situations, light sedation has been proposed, and some series have reported its use in up to $20 \%$ of patients (Hilbert et al., 2015). DEX has been used in this setting considering its sedative and analgesic effect, without depressing the respiratory center or interfering with airway protection, in addition to its excellent safety profile (Hilbert et al., 2015). Current evidence suggests that it is a safe choice, especially in centers where there is a specialized NIV team (Hilbert et al., 2015). Regarding its effectiveness, the literature is scarce and otherwise contradictory.

\section{DEX and Delirium}

Delirium is a common problem in clinical medicine, which is defined as an acute alteration of attention and awareness, attributable to a general medical state (American Psychiatric Association, 2013). In a comprehensive review (Inouye et al., 2014), the highest incidence rates were observed in ICU and postoperative care settings, ranging between 19 and $82 \%$. Although usually transient, it is associated with worse clinical outcomes, including longer hospital length of stay, increased costs, more days on mechanical ventilation, and long-term cognitive impairment and dependence (Pun and Ely, 2007). Moreover, patients who develop delirium in the ICU 
experience a threefold increase in six-month mortality risk compared to matched, non-delirious ICU patients (Ely et al., 2004). Among the modifiable risk factors, the use of sedatives and opioid agents has been identified as one of the most relevant, conferring a relative risk of 4.5 in validated predictive models (Inouye et al., 2014). Hence, it is not surprising other drugs have been tested to provide analgesia or light sedation with a lower delirium risk. Several systematic reviews and meta-analyses have evaluated DEX versus opioids, benzodiazepines, and propofol in terms of delirium occurrence (Mo and Zimmermann, 2013; Pasin et al., 2014; Duan et al., 2018; Flükiger et al., 2018). The most recent one by Flükiger et al. (2018) included 25 trials regarding delirium prevention and three regarding its treatment. The authors found that the use of DEX was associated with significantly minor incidence of delirium when compared to the placebo group, standard sedatives, or opioids. In terms of treatment, the small sample and different comparators made it impossible to argue in favor of or against its use. Recently, prophylactic nightly use of DEX has shown to reduce delirium (Skrobik et al., 2018). The results of this industry-funded, twocenter, double-blind, placebo-controlled trial have not been replicated but remain promising.

Current published clinical guidelines (Devlin et al., 2018) do not directly support the use of DEX for delirium prevention. Still, they do acknowledge the use of DEX, as a sedoanalgesia, is associated with a lower incidence of delirium compared to strategies based on benzodiazepines or opioids. No recommendations are made concerning its prophylactic nightly use. Finally, regarding delirium treatment, guidelines suggest the use of DEX in patients undergoing mechanical ventilation, in which agitation precludes weaning/extubation.

\section{DEX in Neurological Injury}

Scare evidence exists for the neuroprotective effects of DEX in children following neurological injury (Alam et al., 2017). In addition, there are no trials showing the long-term effects of DEX on memory acquisition in children; this is probably due to the inherent challenges associated with designing trials in children. As a result, clinical evidence for the neuroprotective effects of dexmedetomidine in children is limited to cases of delirium following anesthetic infusion, and sedation in critical care patients (Sottas, 2017).

Intracranial lesions or trauma-related damage activate immune inflammation and neuroendocrine responses, causing ischemic brain injury. Studies have shown that inflammatory pathways mediated by neuroendocrine hormones and proinflammatory cytokines is implicated in the pathophysiology of ischemic brain injury. Alpha2-adrenoceptor agonist, dexmedetomidine, is used as neuroprotectant in anesthetic procedures (Jiang et al., 2017). However, meta-analyses to evaluate the neuroprotection of dexmedetomidine against ischemic brain injury are still lacking.

DEX exerts protective effects on brain injury through multiple mechanisms, such as decreasing local inflammation and improving the cerebral oxygen metabolism (Oh-Nishi et al., 2009). These mechanisms underlay the effect of DEX in reducing the ischemic zona and infarct size in an animal model of brain hypoxia-ischemia injury (Ren et al., 2016). Experimental approaches indicated that DEX decreases tumor necrosis factor (TNF)- $\alpha$, interleukin (IL)-6 levels; and maintains a high level of superoxide dismutase (SOD) activity (Wang et al., 2015). In addition, DEX achieves hemodynamic stability and attenuates the stress-related increase of intracranial pressure (Schomer et al., 2019). In this case, the modulation of inflammatory and stress hormones levels are all relevant predictors of clinical outcome following ischemic brain injury (Sahay et al., 2018).

\section{DEX and Sepsis}

Other effects of DEX have been shown in vitro, such as antiinflammatory mechanism in sepsis. These effects are mediated by its action on adrenergic receptors that trigger NF-kB inhibition and level reduction of TNF- $\alpha$, IL-6, IL-8, and HMGB1 (Kawasaki et al., 2013). Moreover, in vivo sepsis, the vagus nerve and $\alpha 7 \mathrm{nAChR}$-mediated cholinergic anti-inflammatory pathway are required for the anti-inflammatory effect of DEX (Xiang et al., 2014).

Patients that develop sepsis may have marked respiratory and cardiovascular depression. Early stages of sepsis are associated with a drop in the systemic vascular resistance, high cardiac output, and a hypercontractile state (Yuki and Murakami, 2015). The improvement of the sepsis management often requires that patients receive anesthesia as well as analgesia. This is due to the unstable cardiovascular state, changes that exacerbate the cardiac dysfunction. Anesthetic drugs in this setting, should not inhibit compensatory hemodynamic responses. Unfortunately, current intravenous drugs and inhalational pharmacological agents do not meet these considerations (Yuki and Murakami, 2015; Cata et al., 2019). However, DEX seems promising in this context, and mechanistic, pharmacodynamic, and pharmacokinetic studies with DEX in critical septic patients have increased in recent years. Recent evidence in septic shock sedated patients have shown that for a comparable level of sedation, switching from propofol to dexmedetomidine resulted in a reduction of norepinephrine requirements in septic shock patients (Morelli et al., 2019).

Table 3 shows the benefits of adding DEX in different clinical settings.

\section{CONCLUDING REMARKS}

Dexmedetomidine is a highly selective alpha-2 receptor agonist. Since its approval by the FDA for sedation in the ICU, its applications have expanded significantly because of its unique mechanism of action, minimal effect on the respiratory drive, and ideal safety profile. Its applications include premedication for pediatric and adult patient populations, procedural sedation and monitored anesthesia care, adjuvant for general and regional anesthesia, perioperative pain control, and postoperative delirium. Clinical evidence show that dexmedetomidine has 
TABLE 3 | Benefits of adding DEX in different clinical settings.

\begin{tabular}{|c|c|c|}
\hline Clinical scenario & $\begin{array}{l}\text { Benefits of } \\
\text { using DEX }\end{array}$ & References \\
\hline $\begin{array}{l}\text { Peri-procedural } \\
\text { sedation }\end{array}$ & $\begin{array}{l}\text { Effective } \\
\text { sedation in } \\
\text { diverse } \\
\text { procedural } \\
\text { scenarios. } \\
\text { Diverse } \\
\text { administration } \\
\text { routes. } \\
\text { Reduces } \\
\text { sympathetic } \\
\text { and stress } \\
\text { response to } \\
\text { surgery. } \\
\text { Sparing effects } \\
\text { of anesthetic } \\
\text { agents } \\
\text { Reduces } \\
\text { postoperative } \\
\text { delirium, } \\
\text { shivering and } \\
\text { pain }\end{array}$ & $\begin{array}{l}\text { Dyck et al., 1993; Khan et al., 1999; } \\
\text { Bhana et al., 2000; Dutta et al., 2000; } \\
\text { Venn et al., 2002; Anttila et al., 2003; } \\
\text { Petroz et al., 2006; Sun et al., 2008; } \\
\text { Potts et al., 2009; Su et al., 2010; Lin } \\
\text { et al., 2011; lirola et al., 2011b; Schnabel } \\
\text { et al., 2013a; Schnabel et al., 2013b; } \\
\text { Piao and Wu, 2014; Cortinez et al., 2015; } \\
\text { Hannivoort et al., 2015; Lewis et al., } \\
\text { 2015; Liu et al., 2015; Mahmoud and } \\
\text { Mason, 2015; Yoo et al., 2015; Zhang } \\
\text { et al., 2015; Hoffman and Hamner, 2016; } \\
\text { Scott-Warren and Sebastian, 2016; Su X. } \\
\text { et al., 2016; Wiczling et al., 2016; Liu } \\
\text { et al., 2017; Sottas, 2017; Weerink et al., } \\
2017\end{array}$ \\
\hline ICU & $\begin{array}{l}\text { Reduces ICU } \\
\text { stays and } \\
\text { duration of } \\
\text { mechanical } \\
\text { ventilation } \\
\text { Sparing effects } \\
\text { of } \\
\text { benzodiazepines } \\
\text { Delirium } \\
\text { prevention }\end{array}$ & $\begin{array}{l}\text { Bhana et al., 2000; Su X. et al., 2016; } \\
\text { Chlan et al., 2017; Nunes et al., 2018; } \\
\text { Flükiger et al., } 2018\end{array}$ \\
\hline $\begin{array}{l}\text { Invasive } \\
\text { Mechanical } \\
\text { Ventilation }\end{array}$ & $\begin{array}{l}\text { Shorter Time to } \\
\text { extubation and } \\
\text { ICU stay. } \\
\text { Decrease } \\
\text { incidence of } \\
\text { delirium }\end{array}$ & $\begin{array}{l}\text { Fraser et al., 2013; Reade and Finfer, } \\
\text { 2014; Su et al., 2016; Hayashida et al., } \\
\text { 2016; Nunes et al., } 2018\end{array}$ \\
\hline $\begin{array}{l}\text { Non-invasive } \\
\text { Ventilation }\end{array}$ & $\begin{array}{l}\text { Sedation and } \\
\text { analgesia } \\
\text { without } \\
\text { respiratory } \\
\text { depression }\end{array}$ & Hilbert et al., 2015 \\
\hline Delirium & $\begin{array}{l}\text { Reduces } \\
\text { incidence of } \\
\text { delirium in ICU } \\
\text { and } \\
\text { postoperative } \\
\text { period }\end{array}$ & $\begin{array}{l}\text { Mo and Zimmermann, 2013; Pasin et al., } \\
\text { 2014; Mahmoud and Mason, 2015; Duan } \\
\text { et al., 2018; Flükiger et al., 2018; Skrobik } \\
\text { et al., } 2018\end{array}$ \\
\hline Neurological Injury & $\begin{array}{l}\text { Potential } \\
\text { neuroprotection } \\
\text { in young } \\
\text { children. } \\
\text { Potential } \\
\text { neuroprotection } \\
\text { in Ischemic } \\
\text { brain injury }\end{array}$ & $\begin{array}{l}\text { Ren et al., 2016; Alam et al., 2017; } \\
\text { Sottas, 2017; Schomer et al., } 2019\end{array}$ \\
\hline Sepsis & $\begin{array}{l}\text { Anti-inflamatory } \\
\text { effects in sepsis. } \\
\text { Potential } \\
\text { hemodynamic } \\
\text { stability }\end{array}$ & Xiang et al., 2014; Morelli et al., 2019 \\
\hline
\end{tabular}

little effect on the respiratory drive; it still can cause airway obstruction in combination with other anesthetic agents (Nguyen et al., 2017).

Preclinical studies with DEX on murine models have revealed protective effects, including the inhibition of proinflammatory cytokine production (Taniguchi et al., 2004). In vitro studies with human whole blood samples have shown that DEX significantly suppresses Lipopolysaccharide induced proinflammatory mediators dose-dependently (Kawasaki et al., 2013). Clinical investigations with human subjects evaluating the effects of DEX on serum inflammatory cytokines during perioperative conditions show inconsistencies in the outcomes (Liu and Qian, 2013; Liang et al., 2017)

Multiple trials and meta-analyses also suggest that DEX use is associated with less delirium and cognitive disturbance, faster weaning from mechanical ventilation, and decreased time to extubation compared with other sedative agents (Shehabi et al., 2019; Yamamoto et al., 2019). As such, DEX seems to be an ideal primary anesthetic agent in the sedation of intubated and mechanically ventilated critical patients.

Regarding their molecular effects, DEX pre-, intra- and postconditioning treatments showed neuroprotective and cardioprotective effects reduced cell necrosis, although only preconditioning showed antiapoptotic mechanisms (Ren et al., 2016; Deng et al., 2019). Dexmedetomidine treatments also reduced IL- 6 and TNF- $\alpha$ levels, especially in the preconditioning groups. Oxidative stress is attenuated with all DEX-preconditioning treatments, but only with the higher dose in the intraconditioning group, and no effects were observed in the postconditioning (Rodriguez-Gonzalez, 2016; Cheng et al., 2018). According to these changes, conditioning strategies increased BDNF levels and attenuate mitochondrial dysfunction in vivo and in vitro models of IR injury (Huang and Jiang, 2019).

Cardiac preconditioning effects associated with DEX administration validated in animal models are shown in Figure 2.

Overall, evidence shows that DEX may attenuate the mortality and inhibit inflammatory processes, as it enhances the activity of the immune system while reducing its systemic reaction and lowering cytokine levels. Moreover, DEX succeeds in alleviating heart injury during sepsis, acting beneficially for microcirculation, and shows a neuroprotective role by inhibiting cell death pathways. Various molecular signaling pathways, such as mitochondria or the modulation of transcriptional factors, are under study in both in vivo and in vitro models.

Therefore, we can say with the reviewed evidence that DEX can be used as a drug for the study of translational models from the cellular and animal point of view and in clinical trials with humans which including cardiovascular and ventilator outcomes. The biological activities associated with DEX continues keep growing, and its diverse effects suggest that it may offer a novel therapeutic approach for the treatment of human diseases with $\mathrm{I} / \mathrm{R}$ involvement. 


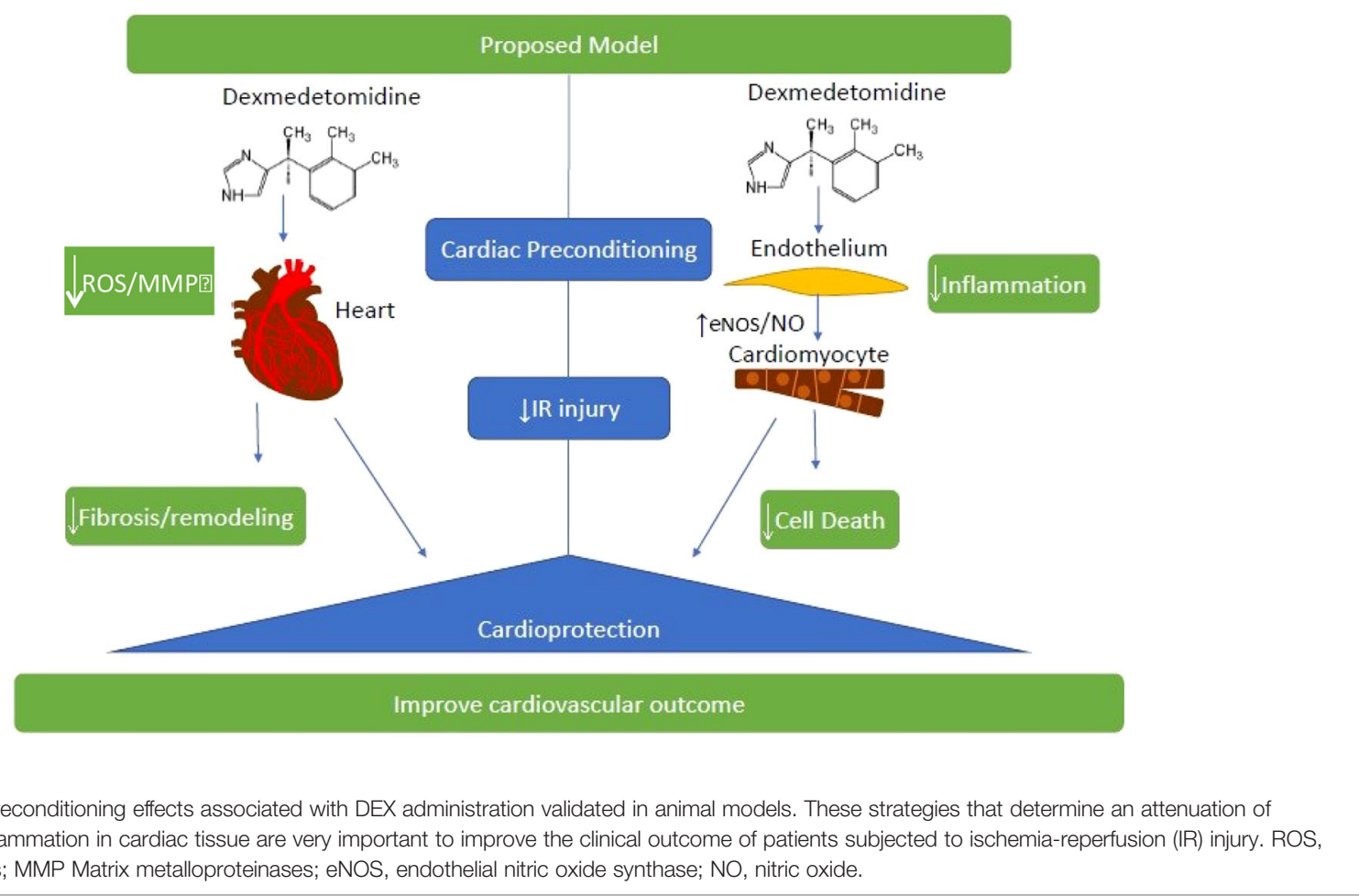

\section{AUTHOR CONTRIBUTIONS}

RC: designed the manuscript and the structure of the themes and wrote about animal models and basic targets of DEX. MI and IC: wrote about human pharmacokinetics of DEX. CC-P: provided evidence of DEX on the mitochondrial protection and clinical outcomes. RC: wrote about DEX on cardioprotection. PV-E, RB, and DR: wrote about DEX in different clinical settings. DT and AM: contributed to the design of the figures and the configuration of the references.

\section{REFERENCES}

Adams, J. P., and Murphy, P. G. (2000). Obesity in anaesthesia and intensive care. Br. J. Anaesth. 85, 91-108. doi: 10.1093/bja/85.1.91

Alam, A., Suen, K. C., Hana, Z., Sanders, R. D., Maze, M., and Ma, D. (2017). Neuroprotection and neurotoxicity in the developing brain: an update on the effects of dexmedetomidine and xenon. Neurotoxicol. Teratol. 60, 102-116. doi: 10.1016/j.ntt.2017.01.001

Al-Metwalli, R. R., Mowafi, H. A., Ismail, S. A., Siddiqui, A. K., Al-Ghamdi, A. M., Shafi, M. A., et al. (2008). Effect of intra-articular dexmedetomidine on postoperative analgesia after arthroscopic knee surgery. Br. J. Anaesth. 101, 395-399. doi: 10.1093/bja/aen184

American Psychiatric Association (2013). Diagnostic and statistical manual of mental disorders: DSM-5 (Washington, D.C: American Psychiatric Association). doi: 10.1176/appi.books.9780890425596

Anttila, M., Penttila, J., Helminen, A., Vuorilehto, L., and Scheinin, H. (2003). Bioavailability of dexmedetomidine after extravascular doses in healthy subjects. Br. J. Clin. Pharmacol. 56, 691-693. doi: 10.1046/j.13652125.2003.01944.x
JGF: contributed to the design of the Tables, figures and the drafting of the conclusions.

\section{FUNDING}

This work was supported by "Fondo Nacional de Desarrollo Científico y Tecnológico" (FONDECYT) Grants 1180387, Gobierno de Chile (JGF). Additional funding was provided by Grant SANTANDER-UNIVERSIA 2015, Banco Santander, Chile (RC).

Arcangeli, A., D'Alo, C., and Gaspari, R. (2009). Dexmedetomidine use in genera anaesthesia. Curr. Drug Targets 10, 687-695. doi: 10.2174/138945009788982423

Barr, J., Fraser, G. L., Puntillo, K., Ely, E. W., Gélinas, C., Dasta, J., et al. (2013). Clinical practice guidelines for the management of pain, agitation, and delirium in adult patients in the intensive care unit. Crit. Care Med. 41, 263306. doi: 10.1097/CCM.0b013e3182783b72

Barrey, E., Saint-Auret, G., Bonnamy, B., Damas, D., Boyer, O., and Gidrol, X. (2011). Pre-microRNA and mature microRNA in human mitochondria. PloS One 6, e20220. doi: 10.1371/journal.pone.0020220

Bekker, A. Y., Basile, J., Gold, M., Riles, T., Adelman, M., Cuff, G., et al. (2004). Dexmedetomidine for awake carotid endarterectomy: efficacy, hemodynamic profile, and side effects. J. Neurosurg. Anesthesiol. 16, 126-135. doi: 10.1097/ 00008506-200404000-00004

Bekker, A., Sturaitis, M., Bloom, M., Moric, M., Golfinos, J., Parker, E., et al. (2008). The effect of dexmedetomidine on perioperative hemodynamics in patients undergoing craniotomy. Anesth. Analg. 107, 1340-1347. doi: 10.1213/ ane.0b013e3181804298

Bekker, A., Haile, M., Kline, R., Didehvar, S., Babu, R., Martiniuk, F., et al. (2013). The effect of intraoperative infusion of dexmedetomidine on the quality of 
recovery after major spinal surgery. J. Neurosurg. Anesthesiol. 25, 16-24. doi: 10.1097/ANA.0b013e31826318af

Bello, G., De Santis, P., and Antonelli, M. (2018). Non-invasive ventilation in cardiogenic pulmonary edema. Ann. Transl. Med. 6, 355. doi: 10.21037/ atm.2018.04.39

Benet, L. (2002). Changes in plasma protein binding have little clinical relevance. Clin. Pharmacol. Ther. 71, 115-121. doi: 10.1067/mcp.2002.121829

Bergese, S. D., Khabiri, B., Roberts, W. D., Howie, M. B., McSweeney, T. D., and Gerhardt, M. A. (2007). Dexmedetomidine for conscious sedation in difficult awake fiberoptic intubation cases. J. Clin. Anesth. 19, 141-144. doi: 10.1016/ j.jclinane.2006.07.005

Bhana, N., Goa, K. L., and McClellan, K. J. (2000). Dexmedetomidine. Drugs 59, 263-268. doi: 10.2165/00003495-200059020-00012

Biccard, B., Goga, S., and de Beurs, J. (2008). Dexmedetomidine and cardiac protection for non-cardiac surgery: a meta-analysis of randomised controlled trials. Anaesthesia 63, 4-14. doi: 10.1111/j.1365-2044.2007.05306.x

Borgens, R. B., and Liu-Snyder, P. (2012). Understanding secondary injury. Q. Rev. Biol. 87, 89-127. doi: 10.1086/665457

Carlucci, A., Richard, J. C., Wysocki, M., Lepage, E., and Brochard, L. (2001). Noninvasive versus conventional mechanical ventilation: an epidemiologic survey. Am. J. Respir. Crit. Care Med. 163, 874-880. doi: 10.1164/ ajrccm.163.4.2006027

Carr, Z. J., Cios, T. J., Potter, K. F., and Swick, J. T. (2018). Does dexmedetomidine ameliorate postoperative cognitive dysfunction? A Brief Review of the Recent Literature. Curr. Neurol. Neurosci. Rep. 18, 64. doi: 10.1007/s11910-018-0873-z

Cata, J. P., Owusu-Agyemang, P., Kapoor, R., and Lonnqvist, P. A. (2019). Impact of anesthetics, analgesics, and perioperative blood transfusion in pediatric cancer patients: a comprehensive review of the literature. Anesth. Analg. 129 (6), 1653-1665. doi: 10.1213/ANE.0000000000004314

Chen, J., Shen, N., Duan, X., and Guo, Y. (2018a). An investigation of the mechanism of dexmedetomidine in improving postoperative cognitive dysfunction from the perspectives of alleviating neuronal mitochondrial membrane oxidative stress and electrophysiological dysfunction. Exp. Ther. Med. 15, 2037-2043. doi: 10.3892/etm.2017.5589

Chen, Q., Aluri, H., and Lesnefsky, E. J. (2018b). Cardiac protection by moving the mitochondria? Int. J. Cardiol. 271, 256-257. doi: 10.1016/j.ijcard.2018. 06.051

Cheng, X., Hu, J., Wang, Y., Ye, H., Li, X., Gao, Q., et al. (2018). Effects of Dexmedetomidine Postconditioning on Myocardial Ischemia/Reperfusion Injury in Diabetic Rats: Role of the PI3K/Akt-Dependent Signaling Pathway. J. Diabetes Res. 2018, 3071959. doi: 10.1155/2018/3071959

Cheung, C. W., Qiu, Q., Ying, A. C., Choi, S. W., Law, W. L., and Irwin, M. G. (2014). The effects of intra-operative dexmedetomidine on postoperative pain, side-effects and recovery in colorectal surgery. Anaesthesia 69, 1214-1221. doi: 10.1111/anae. 12759

Chlan, L., Skaar, D., Tracy, M., Hayes, S., Hetland, B., Savik, K., et al. (2017). Safety and acceptability of patient-administered sedation during mechanical ventilation. Am. J. Crit. Care 26, 288-296. doi: 10.4037/ajcc2017408

Cimen, Z. S., Hanci, A., Sivrikaya, G. U., Kilinc, L. T., and Erol, M. K. (2013). Comparison of buccal and nasal dexmedetomidine premedication for pediatric patients. Paediatr. Anaesth. 23, 134-138. doi: 10.1111/pan.12025

Constantin, J. M., Momon, A., Mantz, J., Payen, J. F., De Jonghe, B., Perbet, S., et al. (2016). Efficacy and safety of sedation with Dexmedetomidine in critical care patients: A meta-analysis of randomized controlled trials. Anaesth. Crit. Care Pain Med. 35, 7-15. doi: 10.1016/j.accpm.2015.06.012

Cooper, L., Candiotti, K., Gallagher, C., Grenier, E., Arheart, K. L., and Barron, M. E. (2011). A randomized, controlled trial on dexmedetomidine for providing adequate sedation and hemodynamic control for awake, diagnostic transesophageal echocardiography. J. Cardiothorac. Vasc. Anesth. 25, 233237. doi: $10.1053 /$ j.jvca.2010.06.006

Cormack, J. R., Orme, R. M., and Costello, T. G. (2005). The role of alpha2agonists in neurosurgery. J. Clin. Neurosci. 12, 375-378. doi: 10.1016/ j.jocn.2004.06.008

Cortinez, L. I., Anderson, B. J., Holford, N. H. G., Puga, V., de la Fuente, N., and Auad, H. (2015). Dexmedetomidine pharmacokinetics in the obese. Eur. J. Clin. Pharmacol. 71, 1501-1508. doi: 10.1007/s00228-015-1948-2
Cunningham, F. E., Baughman, V. L., Tonkovich, L., Lam, N., and Layden, T. (1999). Pharmacokinetics of dexmedetomidine in patients with hepatic failure. Clin. Pharmacol. Ther. 65, 128. doi: 10.1016/S0009-9236(99)80045-9

Curtis, F. G., Vianna, P. T., Viero, R. M., Fiorio, P. M., Silva, L. M., Braz, J. R., et al. (2011). Dexmedetomidine and S+-ketamine in ischemia and reperfusion injury in the rat kidney. Acta Cir. Bras. 26, 202-206. doi: 10.1590/S010286502011000300008

Cussac, D., Schaak, S., Gales, C., Flordellis, C., Denis, C., and Paris, H. (2002). Alpha(2B)-Adrenergic receptors activate MAPK and modulate proliferation of primary cultured proximal tubule cells. Am. J. Physiol. Renal Physiol. 282, F943-F952. doi: 10.1152/ajprenal.0108.2001

Dahmani, S., Paris, A., Jannier, V., Hein, L., Rouelle, D., and Scholz, J. (2008). Dexmedetomidine increases hippocampal phosphorylated extracellular signalregulated protein kinase 1 and 2 content by an alpha 2 -adrenoceptorindependent mechanism: evidence for the involvement of imidazoline I1 receptors. Anesthesiology 108, 457-466. doi: 10.1097/ALN.0b013e318164ca81

Dahmani, S., Rouelle, D., Gressens, P., and Mantz, J. (2010). Characterization of the postconditioning effect of dexmedetomidine in mouse organotypic hippocampal slice cultures exposed to oxygen and glucose deprivation. Anesthesiology 112, 373-383. doi: 10.1097/ALN.0b013e3181ca6982

Dai, W., Tang, M., and He, K. (2018). The effect and safety of dexmedetomidine added to ropivacaine in brachial plexus block: a meta-analysis of randomized controlled trials. Med. (Baltimore) 97, e12573. doi: 10.1097/ MD.0000000000012573

DeBiasi, E. M., Akgün, K. M., and Pisani, M. (2015). Awake or Sedated: Trends in the Evaluation and Management of Agitation in the Intensive Care Unit. Semin. Respir. Crit. Care Med. 36, 899-913. doi: 10.1055/s-0035-1564875

Deng, L., Chen, H., Wei, N., Zhang, Z., and Wang, G. (2019). The cardioprotective effect of dexmedetomidine on regional ischemia/reperfusion injury in type 2 diabetic rat hearts. Microvasc. Res. 123, 1-6. doi: 10.1016/j.mvr.2018.08.006

Deutsch, E., and Tobias, J. D. (2007). Hemodynamic and respiratory changes following dexmedetomidine administration during general anesthesia: Sevoflurane vs. desflurane. Paediatr. Anaesth. 17, 438-444. doi: 10.1111/ j.1460-9592.2006.02139.x

Devlin, J. W., Skrobik, Y., Gélinas, C., Needham, D. M., Slooter, A. J. C., Pandharipande, P. P., et al. (2018). Clinical practice guidelines for the prevention and management of pain, agitation/sedation, delirium, immobility, and sleep disruption in adult patients in the ICU. Crit. Care Med. 46, e825-e873. doi: 10.1097/CCM.0000000000003299

Devlin, J. W. (2008). The pharmacology of oversedation in mechanically ventilated adults. Curr. Opin. Crit. Care 14, 403-407. doi: 10.1097/MCC. 0b013e32830280b3

Du, T., Li, B., Liu, S., Zang, P., Prevot, V., Hertz, L., et al. (2009). ERK phosphorylation in intact, adult brain by alpha(2)-adrenergic transactivation of EGF receptors. Neurochem. Int. 55, 593-600. doi: 10.1016/j.neuint.2009. 05.016

Duan, X., Coburn, M., Rossaint, R., Sanders, R. D., Waesberghe, J. V., and Kowark, A. (2018). Efficacy of perioperative dexmedetomidine on postoperative delirium: systematic review and meta-analysis with trial sequential analysis of randomised controlled trials. Br. J. Anaesth. 121, 384-397. doi: 10.1016/ j.bja.2018.04.046

Dutta, S., Lal, R., Karol, M. D., Cohen, T., and Ebert, T. (2000). Influence of cardiac output on dexmedetomidine pharmacokinetics. J. Pharm. Sci. 89, 519-527. doi: 10.1002/(SICI)1520-6017(200004)89:4<519::AID-JPS9>3.0.CO;2-U

Dyck, J. B., Maze, M., Haack, C., Vuorilehto, L., and Shafer, S. L. (1993). The pharmacokinetics and hemodynamic effects of intravenous and intramuscular dexmedetomidine hydrochloride in adult human volunteers. Anesthesiology 78, 813-820. doi: 10.1097/00000542-199305000-00002

Ebert, T. J., Hall, J. E., Barney, J. A., Uhrich, T. D., and Colinco, M. D. (2000). The effects of increasing plasma concentrations of dexmedetomidine in humans. Anesthesiology 93, 382-394. doi: 10.1097/00000542-200008000-00016

El-Hennawy, A. M., Abd-Elwahab, A. M., Abd-Elmaksoud, A. M., El-Ozairy, H. S., and Boulis, S. R. (2009). Addition of clonidine or dexmedetomidine to bupivacaine prolongs caudal analgesia in children. Br. J. Anaesth. 103, 268274. doi: $10.1093 /$ bja/aep159

Ely, E. W., Shintani, A., Truman, B., Speroff, T., Gordon, S. M., Harrell, F. E., et al. (2004). Delirium as a predictor of mortality in mechanically ventilated patients 
in the intensive care unit. JAMA 291, 1753-1762. doi: 10.1001/ jama.291.14.1753

Figueroa, X. F., Poblete, M. I., Boric, M. P., Mendizabal, V. E., Adler-Graschinsky, E., and Huidobro-Toro, J. P. (2001). Clonidine-induced nitric oxide-dependent vasorelaxation mediated by endothelial a2-adrenoceptor activation. $\mathrm{Br} . \mathrm{J}$. Pharmacol. 134, 957-968. doi: 10.1038/sj.bjp.0704320

Filbey, W. A., Sanford, D. T., Baghdoyan, H. A., Koch, L. G., Britton, S. L., and Lydic, R. (2014). Eszopiclone and dexmedetomidine depress ventilation in obese rats with features of metabolic syndrome. Sleep 37, 871-880. doi: 10.5665/sleep. 3650

Flükiger, J., Hollinger, A., Speich, B., Meier, V., Tontsch, J., Zehnder, T., et al. (2018). Dexmedetomidine in prevention and treatment of postoperative and intensive care unit delirium: a systematic review and meta-analysis. Ann. Intensive Care 8, 92. doi: 10.1186/s13613-018-0437-z

Flatters, S. J., and Bennett, G. J. (2006). Studies of peripheral sensory nerves in paclitaxel-induced painful peripheral neuropathy: evidence for mitochondrial dysfunction. Pain 122, 245-257. doi: 10.1016/j.pain.2006.01.037

Fraser, G. L., Devlin, J. W., Worby, C. P., Alhazzani, W., Barr, J., Dasta, J. F., et al. (2013). Benzodiazepine versus nonbenzodiazepine-based sedation for mechanically ventilated, critically ill adults: a systematic review and metaanalysis of randomized trials. Crit. Care Med. 41, S30-S38. doi: 10.1097/ CCM.0b013e3182a16898

Fu, C., Dai, X., Yang, Y., Lin, M., Cai, Y., and Cai, S. (2017). Dexmedetomidine attenuates lipopolysaccharide-induced acute lung injury by inhibiting oxidative stress, mitochondrial dysfunction and apoptosis in rats. Mol. Med. Rep. 15 (1), 131-138.

Gerlach, A. T., Dasta, J. F., Steinberg, S., Martin, L. C., and Cook, C. H. (2009). A new dosing protocol reduces dexmedetomidine-associated hypotension in critically ill surgical patients. J. Crit. Care 24, 568-574. doi: 10.1016/ j.jcrc.2009.05.015

Ghali, A., Mahfouz, A. K., Ihanamäki, T., and El Btarny, A. M. (2011). Dexmedetomidine versus propofol for sedation in patients undergoing vitreoretinal surgery under sub-Tenon's anesthesia. Saudi J. Anaesth. 5, 3641. doi: 10.4103/1658-354X.76506

Girault, J. A., Costa, A., Derkinderen, P., Studler, J. M., and Toutant, M. (1999). FAK and PYK2/CAKbeta in the nervous system: a link between neuronal activity, plasticity and survival? Trends Neurosci. 22, 257-263. doi: 10.1016/ S0166-2236(98)01358-7

Gong, Z., Ma, L., Zhong, Y. L., Li, J., Lv, J., and Xie, Y. B. (2017). Myocardial protective effects of dexmedetomidine in patients undergoing cardiac surgery: A meta-analysis and systematic review. Exp. Ther. Med. 13, 2355-2361. doi: 10.3892/etm.2017.4227

Gonzales, J. N., Gorshkov, B., Varn, M. N., Zemskova, M. A., Zemskov, E. A., Sridhar, S., et al. (2014). Protective effect of adenosine receptors against lipopolysaccharide-induced acute lung injury. Am. J. Physiol. Lung Cell Mol. Physiol. 306, L497-L507. doi: 10.1152/ajplung.00086.2013

Guler, G., Akin, A., Tosun, Z., Eskitascoglu, E., Mizrak, A., and Boyaci, A. (2005). Single-dose dexmedetomidine attenuates airway and circulatory reflexes during extubation. Acta Anaesthesiol. Scand. 49, 1088-1091. doi: 10.1111/ j.1399-6576.2005.00780.x

Halestrap, A. P. (2009). What is the mitochondrial permeability transition pore? J. Mol. Cell. Cardiol. 46, 821-831. doi: 10.1016/j.yjmcc.2009.02.021

Hanci, V., Yurdakan, G., Yurtlu, S., Turan, I.Ö., and Sipahi, E. Y. (2012). Protective effect of dexmedetomidine in a rat model of $\alpha$-naphthylthiourea-induced acute lung injury. J. Surg. Res. 178, 424-430. doi: 10.1016/j.jss.2012.02.027

Hanna, P., and Milap, C. N. (2008). Clinical Uses of Dexmedetomidine in Pediatric Patient. Paediatr Drugs 10 (1), 49-69.

Hannivoort, L. N., Eleveld, D. J., Proost, J. H., Reyntjens, K. M., Absalom, A. R., Vereecke, H. E., et al. (2015). Development of an optimized pharmacokinetic model of dexmedetomidine using target-controlled infusion in healthy volunteers. Anesthesiology 123, 357-367. doi: 10.1097/ALN.0000000000000740

Harris, D. A., and Das, A. M. (1991). Control of mitochondrial ATP synthesis in the heart. Biochem. J. 280, 561-573. doi: 10.1042/bj2800561

Hayashida, K., Umegaki, T., Ikai, H., Murakami, G., Nishimura, M., and Imanaka, Y. (2016). The relationship between sedative drug utilization and outcomes in critically ill patients undergoing mechanical ventilation. J. Anesth. 30, 763-769. doi: $10.1007 / \mathrm{s} 00540-016-2196-\mathrm{z}$
Hilbert, G., Navalesi, P., and Girault, C. (2015). Is sedation safe and beneficial in patients receiving NIV? Yes Intensive Care Med. 41, 1688-1691. doi: 10.1007/ s00134-015-3935-6

Hodiamont, C. J., Juffermans, N. P., Bouman, C. S., de Jong, M. D., Mathôt, R. A., and van Hest, R. M. (2017). Determinants of gentamicin concentrations in critically ill patients: a population pharmacokinetic analysis. Int. J. Antimicrob. Agents 49, 204-211. doi: 10.1016/j.ijantimicag.2016.10.022

Hofer, R. E., Sprung, J., Sarr, M. G., and Wedel, D. J. (2005). Anaesthesia for a patient with morbid obesity using dexmedetomidine without narcotics. Can. J. Anesth. 52, 176-180. doi: 10.1007/BF03027725

Hoffman, J., and Hamner, C. (2016). Effectiveness of dexmedetomidine use in general anesthesia to prevent postoperative shivering: a systematic review. JBI. Database Syst. Rev. Implement. Rep. 13, 287-313. doi: 10.11124/jbisrir-20152257

Hsu, Y. W., Cortinez, L. I., Robertson, K. M., Keifer, J. C., Sum-Ping, S. T., and Moretti, E. W. (2004). Dexmedetomidine pharmacodynamics: part I: crossover comparison of the respiratory effects of dexmedetomidine and remifentanil in healthy volunteers. Anesthesiology 101, 1066-1076. doi: 10.1097/00000542200411000-00005

Huang, J., and Jiang, Q. (2019). Dexmedetomidine protects against neurological dysfunction in a mouse intracerebral hemorrhage model by inhibiting mitochondrial dysfunction-derived oxidative stress. J. Stroke Cerebrovasc. Dis. 28, 1281-1289. doi: 10.1016/j.jstrokecerebrovasdis.2019.01.016

Huang, X. Z., Tu, W. F., Peng, J., Deng, R. F., Mo, K., Hu, et al. (2015). Effect of preemptive local injection of ropivocaine with dexmedetomidine on mirror pain in rats and its mechanism. Asian Pac. J. Trop. Med. 8, 836-840. doi: 10.1016/j.apjtm.2015.09.010

Hunter, D. R., and Haworth, R. A. (1979). The Ca2+-induced membrane transition in mitochondria. I. The protective mechanisms. Arch. Biochem. Biophys. 195, 453-459. doi: 10.1016/0003-9861(79)90371-0

Ibacache, M., Sanchez, G., Pedrozo, Z., Galvez, F., Humeres, C., Echevarria, G., et al. (2012). Dexmedetomidine preconditioning activates pro-survival kinases and attenuates regional ischemia/reperfusion injury in rat heart. Biochim. Biophys. Acta 1822, 537-545. doi: 10.1016/j.bbadis.2011.12.013

Ickeringill, M., Shehabi, Y., Adamson,, and Ruettimann, U. (2004). Dexmedetomidine infusión without loading dose in surgical patients requiring mechanical ventilation: haemodynamic effects and efficacy. Anaesth. Intensive Care 32, 741-745. doi: 10.1177/0310057X0403200602

Iirola, T., Aantaa, R., Laitio, R., Kentala, E., Lahtinen, M., Wighton, A., et al. (2011a). Pharmacokinetics of prolonged infusion of high-dose dexmedetomidine in critically ill patients. Crit. Care 15, R257. doi: 10.1186/cc10518

Iirola, T., Vilo, S., Manner, T., Aantaa, R., Lahtinen, M., Scheinin, M., et al. (2011b). Bioavailability of dexmedetomidine after intranasal administration. Eur. J. Clin. Pharmacol. 67, 825-831. doi: 10.1007/s00228-011-1002-y

Iirola, T., Ihmsen, H., Laitio, R., Kentala, E., Aantaa, R., Kurvinen, J. P., et al. (2012). Population pharmacokinetics of dexmedetomidine during long-term sedation in intensive care patients. Br. J. Anaesth. 108, 460-468. doi: 10.1093/ bja/aer441

Inouye, S. K., Westendorp, R. G., and Saczynski, J. S. (2014). Delirium in elderly people. Lancet 383, 911-922. doi: 10.1016/S0140-6736(13)60688-1

Jaber, S., Chanques, G., and Jung, B. (2010). Postoperative Noninvasive Ventilation. Anesthesiology 112, 453-61. doi: 10.1097/ALN.0b013e3181c5e5f2

Jalowiecki, P., Rudner, R., Gonciarz, M., Kawecki, P., Petelenz, M., and Dziurdzik, P. (2005). Sole use of dexmedetomidine has limited utility for conscious sedation during outpatient colonoscopy. Anesthesiology 103, 269-273. doi: 10.1097/00000542-200508000-00009

Jiang, C., Xia, M., Wang, M., and Chen, S. (2013). Dexmedetomidine preconditioning protects isolated rat hearts against ischemia/reperfusion injuries and its mechanism. Zhejiang Da Xue Xue Bao Yi Xue Ban. 42, 326-330.

Jiang, L., Hu, M., Lu, Y., Cao, Y., Chang, Y., and Dai, Z. (2017). The protective effects of dexmedetomidine on ischemic brain injury: a meta-analysis. J. Clin. Anesth. 40, 25-32. doi: 10.1016/j.jclinane.2017.04.003

Jorden, V., and Tung, A. (2002). Dexmedetomidine: clinical update. Semin. Anesth. Perioperat. Med. Pain 21, 265-274. doi: 10.1053/sane.2002.34195

Kamibayashi, T., and Maze, M. (2000). Clinical uses of alpha-2 adrenergic agonists. Anesthesiology 93, 1345-1349. doi: 10.1097/00000542-20001100000030 
Kanazi, G. E., Aouad, M. T., Jabbour-Khoury, S. I., Al Jazzar, M. D., Alameddine, M. M., Al-Yaman, R., et al. (2006). Effect of low-dose dexmedetomidine or clonidine on the characteristics of bupivacaine spinal block. Acta Anaesthesiol. Scand. 50, 222-227. doi: 10.1111/j.1399-6576.2006.00919.x

Karhuvaara, S., Kallio, A., Salonen, M., Tuominen, J., and Scheinin, M. (1991). Rapid reversal of alpha 2-adrenoceptor agonist effects by atipamezole in human volunteers. Br. J. Clin. Pharmacol. 1991 (31), 160-165. doi: 10.1111/ j.1365-2125.1991.tb05505.x

Karkoulias, G., Mastrogianni, O., Lymperopoulos, A., Paris, H., and Flordellis, C. (2006). Alpha(2)-Adrenergic receptors activate MAPK and Akt through a pathway involving arachidonic acid metabolism by cytochrome P450dependent epoxygenase, matrix metalloproteinase activation and subtypespecific transactivation of EGFR. Cell Signal. 18, 729-739. doi: 10.1016/ j.cellsig.2005.06.014

Karol, M. D., and Maze, M. (2000). Pharmacokinetics and interaction pharmacodynamics of dexmedetomidine in humans. Best Pract. Res. Clin. Anaesthesiol. 14, 261-269. doi: 10.1053/bean.2000.0081

Karol, M. D. (1996). Pharmacokinetics of dexmedetomidine hydrochloride injection in healthy male volunteers following administration at three different rates, abbott laboratories. Internal Rep.

Kaur, M., and Singh, P. M. (2011). Current role of dexmedetomidine in clinical anesthesia and intensive care. Anesth. Essays Res. 5, 128-133. doi: 10.4103/ 0259-1162.94750

Kawasaki, T., Kawasaki, C., Ueki, M., Hamada, K., Habe, K., and Sata, T. (2013). Dexmedetomidine suppresses proinflammatory mediator production in human whole blood in vitro. J. Trauma Acute Care Surg. 74, 1370-1375. doi: 10.1097/TA.0b013e31828db978

Kaygusuz, K., Gokce, G., Gursoy, S., Ayan, S., Mimaroglu, C., and Gultekin, Y. (2008). A comparison of sedation with dexmedetomidine or propofol during shockwave lithotripsy: a randomized controlled trial. Anesth. Analg. 106, 114119. doi: 10.1213/01.ane.0000296453.75494.64

Keating, G. M., Hoy, S. M., and Lyseng-Williamson, K. A. (2012). Dexmedetomidine: a guide to its use for sedation in the US. Clin. Drug Investig. 32, 561-567. doi: 10.2165/11209820-000000000-00000

Khan, Z. P., Munday, I. T., Jones, R. M., Thornton, C., Mant, T. G., and Amin, D. (1999). Effects of dexmedetomidine on isoflurane requirements in healthy volunteers. 1: pharmacodynamic and pharmacokinetic interactions. Br. J. Anaesth. 83, 372-380. doi: 10.1093/bja/83.3.372

Kim, H. J., Sohn, J. T., Jeong, Y. S., Cho, M. S., Kim, H. J., and Chang, K. C. (2009). Direct effect of dexmedetomidine on rat isolated aorta involves endothelial nitric oxide synthesis and activation of the lipoxygenase pathway. Clin. Exp. Pharmacol. Physiol. 36, 406-412. doi: 10.1111/j.1440-1681.2008.05082.x

Kishikawa, H., Kobayashi, K., Takemori, K., Okabe, T., Ito, K., and Sakamoto, A. (2008). The effects of dexmedetomidine on human neutrophil apoptosis. BioMed. Res. 29, 189-194. doi: 10.2220/biomedres.29.189

Kohli, U., Pandharipande, P., Muszkat, M., Sofowora, G. G., Friedman, E. A., and Scheinin, M. (2012). CYP2A6 genetic variation and dexmedetomidine disposition. Eur. J. Clin. Pharmacol. 68, 937-942. doi: 10.1007/s00228-0111208-z

Kress, J. P., and Hall, J. B. (2014). ICU-Acquired weakness and recovery from critical illness. N. Engl. J. Med. 370, 1626-1635. doi: 10.1056/NEJMra1209390

Kuang, Y., Xiang, Y., Guo, C. X., Zhang, R. R., Yang, G., Hou, G. F., et al. (2016). Population pharmacokinetics study of dexmedetomidine in Chinese adult patients during spinal anesthesia. Int. J. Clin. Pharmacol. Ther. 54, 200-207. doi: 10.5414/CP202521

Kumba, C., and Van der Linden, P. (2008). Effects of sedative agents on metabolic demand. Ann. Fr. Anesth. Reanim. 27, 574-580. doi: 10.1016/ j.annfar.2008.04.010

Kurnik, D., Muszkat, M., Sofowora, G. G., Friedman, E. A., Dupont, W. D., and Scheinin, M. (2008). Ethnic and genetic determinants of cardiovascular response to the selective 2 -adrenoceptor agonist dexmedetomidine. Hypertension 51, 406-411. doi: 10.1161/HYPERTENSIONAHA.107.098939

Lee, S., Kim, B. H., Lim, K., Stalker, D., Wisemandle, W., Shin, S. G., et al. (2012). Pharmacokinetics and pharmacodynamics of intravenous dexmedetomidine in healthy Korean subjects. J. Clin. Pharm. Ther. 37, 698-703. doi: 10.1111/j.13652710.2012.01357.x

Lesnefsky, E. J., Moghaddas, S., Tandler, B., Kerner, J., and Hoppel, C. L. (2001). Mitochondrial dysfunction in cardiac disease: ischemia-reperfusion, aging, and heart failure. J. Mol. Cell. Cardiol. 33, 1065-1089. doi: 10.1006/ jmcc. 2001.1378

Lewis, S. R., Nicholson, A., Smith, A. F., and Alderson, P. (2015). Alpha-2 adrenergic agonists for the prevention of shivering following general anaesthesia. Cochrane Database Syst. Rev. 8, CD011107. doi: 10.1002/ 14651858.CD011107.pub2

Li, L. Q., Wang, C., Xu, H. Y., Lu, H. L., and Zhang, H. Z. (2018). Effects of different doses of intranasal dexmedetomidine on preoperative sedation and postoperative agitation in pediatric with total intravenous anesthesia undergoing adenoidectomy with or without tonsillectomy. Med. (Baltimore) 97, e12140. doi: 10.1097/MD.0000000000012140

Liang, H., Liu, H. Z., Wang, H. B., Zhong, J. Y., Yang, C. X., and Zhang, B. (2017). Dexmedetomidine protects against cisplatin-induced acute kidney injury in mice through regulating apoptosis and inflammation. Inflammation Res. 66, 399-411. doi: 10.1007/s00011-017-1023-9

Lin, L., Guo, X., Zhang, M. Z., Qu, C. J., Sun, Y., and Bai, J. (2011). Pharmacokinetics of dexmedetomidine in Chinese post-surgical intensive care unit patients. Acta Anaesthesiol. Scand. 55, 359-367. doi: 10.1111/ j.1399-6576.2010.02392.x

Liu, H. L., and Qian, Y. N. (2013). Effects of dexmedetomidine on perioperative inflammatory response in patients undergoing valve replacement. Zhongguo Ying Yong Sheng Li Xue Za Zhi. 29, 316-317.

Liu, Z. X., Xu, F. Y., Liang, X., Zhou, M., Wu, L., Wu, J. R., et al. (2015). Efficacy of dexmedetomidine on postoperative shivering: a meta-analysis of clinical trials. Can. J. Anaesth. 62, 816-829. doi: 10.1007/s12630-015-0368-1

Liu, H. C., Lian, Q. Q., Wu, F. F., Wang, C. Y., Sun, W., Zheng, L. D., et al. (2017). Population pharmacokinetics of dexmedetomidine after short intravenous infusion in Chinese children. Eur. J. Drug Metab. Pharmacokinet. 42, 201211. doi: 10.1007/s13318-016-0333-6

Liu, X. R., Li, T., Cao, L., Yu, Y. Y., Chen, L. L., Fan, X. H., et al. (2018). Dexmedetomidine attenuates $\mathrm{H} 2 \mathrm{O} 2$-induced neonatal rat cardiomyocytes apoptosis through mitochondria- and ER-medicated oxidative stress pathways. Mol. Med. Rep. 17, 7258-7264. doi: 10.3892/mmr.2018.8751

Lopez, M. B. (2018). Postanaesthetic shivering - from pathophysiology to prevention. Rom. J. Anaesth. Intensive Care 25, 73-81. doi: 10.21454/ rjaic.7518.251.xum

Lu, Z., Li, W., Chen, H., and Qian, Y. (2018). Efficacy of a dexmedetomidineremifentanil combination compared with a midazolam-remifentanil combination for conscious sedation during therapeutic endoscopic retrograde cholangio-pancreatography: a prospective, randomized, singleblinded preliminary trial. Dig. Dis. Sci. 63, 1633-1640. doi: 10.1007/s10620018-5034-3

Mahmoud, M., and Mason, K. (2015). Dexmedetomidine: review, update, and future considerations of paediatric perioperative and periprocedural applications and limitations. Br. J. Anaesth. 115 (2), 171-182. doi: 10.1093/ bja/aev226

Martin, L. J., Gertz, B., Pan, Y., Price, A. C., Molkentin, J. D., and Chang, Q. (2009). The mitochondrial permeability transition pore in motor neurons: involvement in the pathobiology of ALS mice. Exp. Neurol. 218, 333-346. doi: 10.1016/j.expneurol.2009.02.015

Mason, K., and Lerman, J. (2011). Dexmedetomidine in children: current knowledge and future applications. Anesth. Analg. 113, 1129-1142. doi: 10.1213/ANE.0b013e31822b8629

Mason, K. P., Zurakowski, D., Zgleszewski, S. E., Robson, C. D., Carrier, M., Hickey, P. R., et al. (2008). High dose dexmedetomidine as the sole sedative for pediatric MRI. Paediatr. Anaesth. 18, 403-411. doi: 10.1111/j.14609592.2008.02468.x

Millay, D. P., Sargent, M. A., Osinska, H., Baines, C. P., Barton, E. R., Vuagniaux, G., et al. (2008). Genetic and pharmacologic inhibition of mitochondrialdependent necrosis attenuates muscular dystrophy. Nat. Med. 14, 442-447. doi: $10.1038 / \mathrm{nm} 1736$

Mo, Y., and Zimmermann, A. E. (2013). Role of dexmedetomidine for the prevention and treatment of delirium in intensive care unit patients. Ann. Pharmacother. 47, 869-876. doi: 10.1345/aph.1AR708

Morelli, A., Sanfilippo, F., Arnemann, P., Hessler, M., Kampmeier, T. G., D’Egidio, A., et al. (2019). The effect of propofol and dexmedetomidine sedation on norepinephrine requirements in septic shock patients: a crossover trial. Crit. Care Med. 47, e89-e95. doi: 10.1097/CCM.0000000000003520 
Morgan, G. E., Mikhail, M. S., and Murray, M. J. (2006). In: Preoperative Medication in Clinical Anaethesia. 4th ed. (New York: Mc graw Hill), 248.

Mukhtar, A. M., Obayah, E. M., and Hassona, A. M. (2006). The use of dexmedetomidine in pediatric cardiac surgery. Anesth. Analg. 103, 52-56. doi: 10.1213/01.ane.0000217204.92904.76

Nguyen, V., Tiemann, D., Park, E., and Salehi, A. (2017). Alpha-2 Agonists. Anesthesiol. Clin. 35, 233-245. doi: 10.1016/j.anclin.2017.01.009

Nunes, S. L., Forsberg, S., Blomqvist, H., Berggren, L., Sörberg, M., Sarapohja, T., et al. (2018). Effect of sedation regimen on weaning from mechanical ventilation in the intensive care unit. Clin. Drug Investig. 38, 535-543. doi: 10.1007/s40261-018-0636-2

Obayah, G. M., Refaie, A., Aboushanab, O., Ibraheem, N., and Abdelazees, M. (2010). Addition of dexmedetomidine to bupivacaine for greater palatine nerve block prolongs postoperative analgesia after cleft palate repair. Eur. J. Anaesthesiol. 27, 280-284. doi: 10.1097/EJA.0b013e3283347c15

Oddo, M., Crippa, I., Mehta, S., Menon, D., Payen, J. F., Taccone, F., et al. (2016). Optimizing sedation in patients with acute brain injury. Crit. Care 20, 128. doi: 10.1186/s13054-016-1294-5

Oh-Nishi, A., Saji, M., Satoh, S. Z., Ogata, M., and Suzuki, N. (2009). Late phase of long-term potentiation induced by co-application of $\mathrm{N}$-methyl-d-aspartic acid and the antagonist of NR2B-containing N-methyl-d-aspartic acid receptors in rat hippocampus. Neuroscience 159 (1), 127-135. doi: 10.1016/ j.neuroscience.2008.10.037

Okada, H., Kurita, T., Mochizuki, T., Morita, K., and Sato, S. (2007). The cardioprotective effect of dexmedetomidine on global ischaemia in isolated rat hearts. Resuscitation 74 (2007), 538-545. doi: 10.1016/ j.resuscitation.2007.01.032

Olutoye, O. A., Glover, C. D., Diefenderfer, J. W., McGilberry, M., Wyatt, M. M., Larrier, D. R., et al. (2010). The effect of intraoperative dexmedetomidine on dostoperative analgesia and sedation in pediatric patients undergoing tonsillectomy and adenoidectomy. Anesth. Analg. 111, 490-495. doi: 10.1213/ANE.0b013e3181e33429

Osadnik, C. R., Tee, V. S., Carson-Chahhoud, K. V., Picot, J., Wedzicha, J. A., and Smith, B. J. (2017). Non-invasive ventilation for the management of acute hypercapnic respiratory failure due to exacerbation of chronic obstructive pulmonary disease. Cochrane Database Syst. Rev. 7, CD004104. doi: 10.1002/ 14651858.CD004104.pub4

Ozaki, M., Takeda, J., Tanaka, K., Shiokawa, Y., Nishi, S., Matsuda, K., et al. (2014). Safety and efficacy of dexmedetomidine for long-term sedation in critically ill patients. J. Anesth. 28, 38-50. doi: 10.1007/s00540-013-1678-5

Panzer, O., Moitra, V., and Sladen, R. N. (2009). Pharmacology of sedativeanalgesic agents: dexmedetomidine, remifentanil, ketamine, volatile anesthetics, and the role of peripheral mu antagonists. Crit. Care Clin. 25, 451-469. doi: 10.1016/j.ccc.2009.04.004

Parcellier, A., Tintignac, L. A., Zhuravleva, E., and Hemmings, B. A. (2008). PKB and the mitochondria: AKTing on apoptosis. Cell Signal 20, 21-30. doi: 10.1016/j.cellsig.2007.07.010

Pasin, L., Landoni, G., Nardelli, P., Belletti, A., Di Prima, A. L., Taddeo, D., et al. (2014). Dexmedetomidine reduces the risk of delirium, agitation and confusion in critically Ill patients: a meta-analysis of randomized controlled trials. J. Cardiothorac. Vasc. Anesth. 28, 1459-1466. doi: 10.1053/ j.jvca.2014.03.010

Petroz, G., Sikich, N., James, M., van Dyk, H., Shafer, S. L., Schily, M., et al. (2006). A Phase I, two-center study of the pharmacokinetics and pharmacodynamics of dexmedetomidine in children. Anesthesiology 105, 1098-1110. doi: 10.1097/ 00000542-200612000-00009

Piao, G., and Wu, J. (2014). Systematic assessment of dexmedetomidine as an anesthetic agent: a meta-analysis of randomized controlled trials. Arch. Med. Sci. 10, 19-24. doi: 10.5114/aoms.2014.40730

Pohjoismäki, J. L., and Goffart, S. (2017). The role of mitochondria in cardiac development and protection. Free Radic. Biol. Med. 106, 345-354. doi: 10.1016/ j.freeradbiomed.2017.02.032

Potts, A. L., Anderson, B. J., Warman, G. R., Lerman, J., Diaz, S. M., and Vilo, S. (2009). Dexmedetomidine pharmacokinetics in pediatric intensive care: a pooled analysis. Paediatr. Anaesth. 19, 1119-1129. doi: 10.1111/j.14609592.2009.03133.x
Potts, A. L., Anderson, B. J., Holford, N. H., Vu, T. C., and Warman, G. R. (2010). Dexmedetomidine hemodynamics in children after cardiac surgery. Paediatr. Anaesth. 20, 425-433. doi: 10.1111/j.1460-9592.2010.03285.x

Pun, B. T., and Ely, E. W. (2007). The importance of diagnosing and managing ICU delirium. Chest 132, 624-636. doi: 10.1378/chest.06-1795

Ramachandran, A., Lebofsky, M., Baines, C. P., Lemasters, J. J., and Jaeschke, H. (2011). Cyclophilin D deficiency protects against acetaminophen-induced oxidant stress and liver injury. Free Radical Res. 45, 156-164. doi: 10.3109/ 10715762.2010.520319

Reade, M., and Finfer, S. (2014). Sedation and delirium in the intensive care unit. N. Engl. J. Med. 370, 444-454. doi: 10.1056/NEJMra1208705

Reel, B. (2019). "Dexmedetomidine" n: StatPearls. ed. C. V Maani (Treasure Island (FL): StatPearls Publishing).

Ren, X., Ma, H., and Zuo, Z. (2016). Dexmedetomidine postconditioning reduces brain injury after brain hypoxia-ischemia in neonatal rats. J. Neuroimmune. Pharmacol. 11, 238-247. doi: 10.1007/s11481-016-9658-9

Riker, R. R., Shehabi, Y., Bokesch, P. M., Ceraso, D., Wisemandle, W., Koura, F., et al. (2009). Dexmedetomidine vs midazolam for sedation of critically ill patients: a randomized trial. JAMA 301, 489-499. doi: 10.1001/jama.2009.56

Riquelme, J. A., Westermeier, F., Hall, A. R., Vicencio, J. M., Pedrozo, Z., Ibacache, M., et al. (2016). Dexmedetomidine protects the heart against ischemiareperfusion injury by an endothelial eNOS/NO dependent mechanism. Pharmacol. Res. 103, 318-327. doi: 10.1016/j.phrs.2015.11.004

Rodrigues Júnior, G. R., and do Amaral, J. L. (2004). Influence of sedation on morbidity and mortality in the intensive care unit. Sao Paulo Med. J. 122, 8-11. doi: 10.1590/S1516-31802004000100003

Rodríguez-González, R., Sobrino, T., Veiga, S., López, P., Rodríguez-García, J., Veiras del Río, S., et al. (2016). Neuroprotective Effects of Dexmedetomidine Conditioning Strategies: Evidences From an in Vitro Model of Cerebral Ischemia. Life Sci 144, 162-9. doi: 10.1016/j.lfs.2015.12.007

Roekaerts, P., Prinzen, F., and De Lange, S. (1996). Beneficial effects of dexmedetomidine on ischaemic myocardium of anaesthetized dogs. Br. J. Anaesth. 77, 427-429. doi: 10.1093/bja/77.3.427

Rolle, A., Paredes, S., Cortinez, L., Anderson, B. J., Quezada, N., Solari, S., et al. (2018). Dexmedetomidine metabolic clearance is not affected by fat mass in obese patients. Br. J. Anaesth. 120, 969-977. doi: 10.1016/j.bja.2018.01.040

Sahay, N., Bhadani, U. K., Guha, S., Himanshu, A., Sinha, C., Bara, M., et al. (2018). Effect of dexmedetomidine on intracranial pressures during laparoscopic surgery: a randomized, placebo-controlled trial. J. Anaesthesiol. Clin. Pharmacol. 34, 341-346. doi: 10.4103/joacp.JOACP_171_17

Schaak, S., Cussac, D., Cayla, C., Devedjian, J. C., Guyot, R., Paris, H., et al. (2000). Alpha(2) adrenoceptors regulate proliferation of human intestinal epithelial cells. Gut 47, 242-250. doi: 10.1136/gut.47.2.242

Scheinin, H., Aantaa, R., Anttila, M., Hakola, P., Helminen, A., and Karhuvaara, S. (1998). Reversal of the sedative and sympatholytic effects of dexmedetomidine with a specific alpha2-adrenoceptor antagonist atipamezole: a pharmacodynamic and kinetic study in healthy volunteers. Anesthesiology 89, 574-584. doi: 10.1097/00000542-199809000-00005

Schnabel, A., Meyer-Frießem, C. H., Reichl, S. U., Zahn, P. K., and Pogatzki-Zahn, E. M. (2013a). Is intraoperative dexmedetomidine a new option for postoperative pain treatment? A meta-analysis Randomized Controlled Trials Pain 154, 1140-1149. doi: 10.1016/j.pain.2013.03.029

Schnabel, A., Reichl, S. U., Poepping, D. M., Kranke, P., Pogatzki-Zahn, E. M., and Zahn, P. K. (2013b). Efficacy and safety of intraoperative dexmedetomidine for acute postoperative pain in children: a meta-analysis of randomized controlled trials. Paediatr. Anaesth. 23, 170-179. doi: 10.1111/pan.12030

Schnaider, T. B., Vieira, A. M., Brandao, A. C., and Lobo, M. V. (2005). Intraoperative analgesic effect of epidural ketamine, clonidine or dexmedetomidine for upper abdominal surgery. Rev. Bras. Anestesiol. 55, 525-531. doi: 10.1590/s0034-70942005000500007

Schomer, K. J., Sebat, C. M., Adams, J. Y., Duby, J. J., Shahlaie, K., and Louie, E. L. (2019). Dexmedetomidine for refractory intracranial hypertension. J. Intensive Care Med. 34, 62-66. doi: 10.1177/0885066616689555

Scott-Warren, V. L., and Sebastian, J. (2016). Dexmedetomidine: its use in intensive care medicine and anaesthesia. BJA Educ. 16, 242-246. doi: 10.1093/bjaed/mkv047 
Shariffuddin, I. I., Teoh, W. H., Wahab, S., and Wang, C. Y. (2018). Effect of singledose dexmedetomidine on postoperative recovery after ambulatory ureteroscopy and ureteric stenting: a double blind randomized controlled study. BMC Anesthesiol. 18, 3. doi: 10.1186/s12871-017-0464-6

Shehabi, Y., Howe, B. D., Bellomo, R., Arabi, Y. M., Bailey, M., Bass, F. E., et al. (2019). anzics clinical trials group; spice iii investigators; anzics clinical trials group and the SPICE III Investigators. early sedation with dexmedetomidine in critically Ill patients. N. Engl. J. Med. 380, 2506-2517. doi: 10.1056/ NEJMoa1904710

Silversides, J. A., Major, E., Ferguson, A. J., Mann, E. E., McAuley, D. F., Marshall, J. C., et al. (2017). Conservative fluid management or deresuscitation for patients with sepsis or acute respiratory distress syndrome following the resuscitation phase of critical illness: a systematic review and meta-analysis. Intensive Care Med. 43, 155-170. doi: 10.1007/s00134-016-4573-3

Skrobik, Y., Duprey, M., Hill, N. S., and Devlin, J. W. (2018). Low-dose nocturnal dexmedetomidine prevents ICU delirium. a randomized, placebo-controlled trial. Am. J. Respir. Crit. Care Med. 197, 1147-1156. doi: 10.1164/rccm.201710$19950 \mathrm{C}$

Snapir, A., Posti, J., Kentala, E., Koskenvuo, J., Sundell, J., Tuunanen, H., et al. (2006). Effects of low and high plasma concentrations of dexmedetomidine on myocardial perfusion and cardiac function in healthy male subjects. Anesthesiology 105, 902-910. doi: 10.1097/00000542-200611000-00010

Song, J. C., Gao, H., Qiu, H. B., Chen, Q. B., Cai, M. H., and Zhang, M. Z. (2018). The pharmacokinetics of dexmedetomidine in patients with obstructive jaundice: a clinical trial. PloS One 13, e0207427. doi: 10.1371/ journal.pone. 0207427

Sottas, C. E. (2017). Anderson B.J. Dexmedetomidine: the new all-in-one drug in paediatric anaesthesia? Curr. Opin. Anaesthesiol. 30, 441-451. doi: 10.1097/ ACO. 0000000000000488

Su, F., Nicolson, S. C., Gastonguay, M. R., Barrett, J. S., Adamson, P. C., Kang, D. S., et al. (2010). Population pharmacokinetics of dexmedetomidine in infants after open heart surgery. Anesth. Analg. 110, 1383-1392. doi: 10.1213/ ANE.0b013e3181d783c8

Su, F., Gastonguay, M. R., Nicolson, S. C., DiLiberto, M., Ocampo-Pelland, A., and Zuppa, A. F. (2016). Dexmedetomidine pharmacology in neonates and infants after open heart surgery. Anesth. Analg. 122, 1556-1566. doi: 10.1213/ ANE.0000000000000869

Su, X., Meng, Z. T., Wu, X. H., Cui, F., Li, H. L., Wang, D. X., et al. (2016). Dexmedetomidine for prevention of delirium in elderly patients after noncardiac surgery: a randomised, double-blind, placebo-controlled trial. Lancet 388, 1893-1902. doi: 10.1016/S0140-6736(16)30580-3

Sun, J. H., Han, N., and Wu, X. Y. (2008). Dexmedetomidine in the general anesthesia: a meta-analysis of randomized controlled trials. Chin. J. EvidenceBased Med. 8, 773-780.

Sun, Y., Liu, C., Zhang, Y., Luo, B., She, S., Xu, L., et al. (2014). Low-Dose Intramuscular Dexmedetomidine as Premedication: A Randomized Controlled Trial. Med. Sci. Monit. 20, 2714-2719. doi: 10.12659/MSM.891051

Taittonen, M. T., Kirvela, O. A., Aantaa, R., and Kanto, J. H. (1997). Effect of clonidine and dexmedetomidine premedication on perioperative oxygen consumption and haemodynamic state. Br. J. Anaesth. 78, 400-406. doi: 10.1093/bja/78.4.400

Takamatsu, I., Iwase, A., Ozaki, M., Kazama, T., Wada, K., and Sekiguchi, M. (2008). Dexmedetomidine reduces long-term potentiation in mouse hippocampus. Anesthesiology 108, 94-102. doi: 10.1097/01.anes. 0000296076.04510.e1

Talke, P., Lobo, E., and Brown, R. (2003). Systemically administered $\alpha 2$ agonistinduced peripheral vasoconstriction in humans. Anesthesiology 99, 65-70. doi: 10.1097/00000542-200307000-00014

Tanabe, K., Takai, S., Matsushima-Nishiwaki, R., Kato, K., Dohi, S., and Kozawa, O. (2008). Alpha2 adrenoreceptor agonist regulates protein kinase C-induced heat shock protein 27 phosphorylation in C6 glioma cells. J. Neurochem. 106, 519-528. doi: 10.1111/j.1471-4159.2008.05389.x

Tanabe, K., Matsushima-Nishiwaki, R., Dohi, S., and Kozawa, O. (2010). Phosphorylation status of heat shock protein 27 regulates the interleukin-1 $\beta$ induced interleukin-6 synthesis in C6 glioma cells. Neuroscience 170, 10281034. doi: 10.1016/j.neuroscience.2010.08.014

Taniguchi, T., Kidani, Y., Kanakura, H., Takemoto, Y., and Yamamoto, K. (2004). Effects of dexmedetomidine on mortality rate and inflammatory responses to endotoxin-induced shock in rats. Crit. Care Med. 32, 1322-1326. doi: 10.1097/ 01.CCM.0000128579.84228.2A

Tate, J. A., Devito Dabbs, A., Hoffman, L. A., Milbrandt, E., and Happ, M. B. (2012). Anxiety and Agitation in Mechanically Ventilated Patients. Qual. Health Res. 22, 157-173. doi: 10.1177/1049732311421616

Välitalo, P. A., Ahtola-Sät;ilä, ,. T., Wighton, A., Sarapohja, T., Pohjanjousi, P., and Garratt, C. (2013). Population pharmacokinetics of dexmedetomidine in critically ill patients. Clin. Drug Invest. 33, 579-587. doi: 10.1007/s40261013-0101-1

Venn, R. M., Bradshaw, C. J., Spencer, R., Brealey, D., Caudwell, E., Naughton, C., et al. (1999). Preliminary UK experience of dexmedetomidine, a novel agent for postoperative sedation in the intensive care unit. Anaesthesia 54, 1136-1142. doi: 10.1046/j.1365-2044.1999.01114.x

Venn, R. M., Hell, J., and Grounds, R. M. (2000). Respiratory effects of dexmedetomidine in the surgical patient requiring intensive care. Crit. Care 4, 302-308. doi: 10.1186/cc712

Venn, R. M., Karol, M. D., and Grounds, R. M. (2002). Pharmacokinetics of dexmedetomidine infusions for sedation of postoperative patients requiring intensive care. Br. J. Anaesth. 88, 669-675. doi: 10.1093/bja/88.5.669

Wang, C., and Youle, R. J. (2009). The role of mitochondria in apoptosis. Annu. Rev. Genet. 43, 95-118. doi: 10.1146/annurev-genet-102108-134850

Wang, X. W., Cao, J. B., Lv, B. S., Mi, W. D., Wang, Z. Q., Zhang, C., et al. (2015). Effect of perioperative dexmedetomidine on the endocrine modulators of stress response: a meta-analysis. Clin. Exp. Pharmacol. Physiol. 42, 828-836. doi: 10.1111/1440-1681.12431

Wang, Q., She, Y., Bi, X., Zhao, B., Ruan, X., and Tan, Y. (2017). Dexmedetomidine Protects PC12 Cells from Lidocaine-Induced Cytotoxicity Through Downregulation of COL3A1 Mediated by miR-let-7b. DNA Cell Biol. 36, 518-528. doi: 10.1089/dna.2016.3623

Weerink, M., Struys, M., Hannivoort, L., Barends, C. R. M., Absalom, A. R., and Colin, P. (2017). Clinical Pharmacokinetics and Pharmacodynamics of Dexmedetomidine. Clin. Pharmacokinet. 56, 893-913. doi: 10.1007/s40262017-0507-7

Weng, X., Zhang, X., Lu, X., Wu, J., and Li, S. (2018). Reduced mitochondrial response sensitivity is involved in the antiapoptotic effect of dexmedetomidine pretreatment in cardiomyocytes. Int. J. Mol. Med. 41, 2328-2338. doi: 10.3892/ ijmm.2018.3384

Wiczling, P., Bartkowska-Śn niatkowska, ,. A., Szerkus, O., Siluk, D., RosadaKurasińska, J., Warzybok, J., et al. (2016). The pharmacokinetics of dexmedetomidine during long-term infusion in critically ill pediatric patients: a Bayesian approach with informative priors. J. Pharmacokinet. Pharmacodyn. 43, 315-324. doi: 10.1007/s10928-016-9474-0

Wijeysundera, D. N., Naik, J. S., and Beattie, W. S. (2003). Alpha-2 adrenergic agonists to prevent perioperative cardiovascular complications: a metaanalysis. Am. J. Med. 114, 742-752. doi: 10.1016/S0002-9343(03)00165-7

Wijeysundera, D., Bender, J., and Beattie, W. (2009). Alpha-2 adrenergic agonists for the pre-vention of cardiac complications among patients undergoing surgery. CochraneDatabase Syst. Rev. 4, CD004126. doi: 10.1002/ 14651858.CD004126.pub2

Willigers, H., Prinzen, F., Roekaerts, P., De Lange, S., and Durieux, M. (2003). Dexmedetomidine decreases perioperative myocardial lactate release in dogs, Anesth. Analg 96, 657-664. doi: 10.1213/01.ANE.0000048708.75957.FF

Wu, G. J., Chen, J. T., Tsai, H. C., Chen, T. L., Liu, S. H., and Chen, R. M. (2017). Protection of dexmedetomidine against ischemia/reperfusion-induced apoptotic insults to neuronal cells occurs via an intrinsic mitochondriadependent pathway. J. Cell. Biochem. 118, 2635-2644. doi: 10.1002/jcb.25847

Wunsch, H. (2012). Weighing the costs and benefits of a sedative. JAMA 307, 1195-1197. doi: 10.1001/jama.2012.319

Xiang, H., Hu, B., Li, Z., and Li, J. (2014). Dexmedetomidine controls systemic cytokine levels through the cholinergic anti-inflammatory pathway. Inflammation 37, 1763-1770. doi: 10.1007/s10753-014-9906-1

Yamamoto, T., Mizobata, Y., Kawazoe, Y., Miyamoto, K., Ohta, Y., Morimoto, T., et al. (2019). Incidence, risk factors, and outcomes for sepsis-Associated delirium in patients with mechanical ventilation: a sub-analysis of a multicenter randomized controlled trial. J. Crit. Care. 56, 140-144.

Yang, J., and Kang, Y. (2017). Effect of sedation on respiratory function of patients undergoing mechanical ventilation. Zhonghua Wei Zhong Bing Ji Jiu Yi Xue 29, 857-860. doi: 10.3760/cma.j.issn.2095-4352.2017.09.019 
Yoo, H., Iirola, T., Vilo, S., Manner, T., Aantaa, R., Lahtinen, M., et al. (2015). Mechanism based population pharmacokinetic and pharmacodynamic modeling of intravenous and intranasal dexmedetomidine in healthy subjects. Eur. J. Clin. Pharmacol. 71, 1197-1207. doi: 10.1007/s00228-015-1913-0

Yuan, F., Fu, H., Sun, K., Wu, S., and Dong, T. (2017). Effect of dexmedetomidine on cerebral ischemia-reperfusion rats by activating mitochondrial ATP-sensitive potassium channel. Metab. Brain Dis. 32, 539-546. doi: 10.1007/s11011-016-9945-4

Yuki, K., and Murakami, N. (2015). Sepsis pathophysiology and anesthetic consideration. Cardiovasc. Hematol. Disord. Drug Targets 15, 57-69. doi: 10.2174/1871529X15666150108114810

Zhang, T., Deng, Y., He, P., He., Z., and Wang, X. (2015). Effects of mild hypoalbuminemia on the pharmacokinetics and pharmacodynamics of dexmedetomidine in patients after major abdominal or thoracic surgery. J. Clin. Anesth. 27, 632-637. doi: 10.1016/j.jclinane.2015.06.002

Zhang, W. D., Zhang, H., Wang, H., Zhang, N., Du, C. Y., Yu, J., et al. (2016). Protective effect of dexmedetomidine against glutamate-induced cytotoxicity in PC12 cells and its mechanism. Nan Fang Yi Ke Da Xue Xue Bao. 37, 150-156.

Zhang, Q., Wu, D., Yang, Y., Liu, T., and Liu, H. (2017). Dexmedetomidine alleviates hyperoxia-induced acute lung injury via inhibiting NLRP3 inflammasome activation. Cell Physiol. Biochem. 42, 1907-1919. doi: 10.1159/000479609

Zhu, Y. M., Wang, C. C., Chen, L., Qian, L. B., Ma, L. L., and Yu, J. (2013). Both PI3K/Akt and ERK1/2 pathways participate in the protection by dexmedetomidine against transient focal cerebral ischemia/reperfusion injury in rats. Brain Res. 1494, 1-8. doi: 10.1016/j.brainres.2012.11.047

Conflict of Interest: The authors declare that the research was conducted in the absence of any commercial or financial relationships that could be construed as a potential conflict of interest.

Copyright (c) 2020 Castillo, Ibacache, Cortínez, Carrasco-Pozo, Farías, Carrasco, Vargas-Errázuriz, Ramos, Benavente, Torres and Méndez. This is an open-access article distributed under the terms of the Creative Commons Attribution License (CC BY). The use, distribution or reproduction in other forums is permitted, provided the original author(s) and the copyright owner(s) are credited and that the original publication in this journal is cited, in accordance with accepted academic practice. No use, distribution or reproduction is permitted which does not comply with these terms. 